* Corresponding author. Email: jseewald@whoi.edu, Tel: (508) 289-2966

\section{Submarine Venting of Magmatic Volatiles in the Eastern Manus Basin, Papua New Guinea}

Jeffrey S. Seewald ${ }^{a^{*}}$, Eoghan P. Reeves ${ }^{\mathrm{a}, \mathrm{b}}$, Wolfgang Bach ${ }^{\mathrm{b}}$, Peter J. Saccocia ${ }^{\mathrm{c}}$, Paul R. Craddock $^{\mathrm{a}}$, Wayne C. Shanks III ${ }^{\mathrm{d}}$, Sean P. Sylva ${ }^{\mathrm{a}}$, Thomas Pichler ${ }^{\mathrm{b}}$, Martin Rosner ${ }^{\mathrm{e}}$, Emily Walsh $^{\mathrm{c}}$,

${ }^{a}$ Department of Marine Chemistry and Geochemistry, Woods Hole Oceanographic Institution, 360 Woods Hole Road, Woods Hole, MA 02543, USA

${ }^{\mathrm{c}}$ Department of Geological Sciences, Bridgewater State University, Bridgewater, MA 02325, USA

${ }^{\mathrm{d}}$ U.S. Geological Survey, 973 Denver Federal Center, Denver, CO 80225, USA

${ }^{b}$ Department of Geosciences, University of Bremen, Klagenfurter Str., 28359 Bremen, Germany

31 
The SuSu Knolls and DESMOS hydrothermal fields are located in the back-arc extensional transform zone of the Eastern Manus Basin. In 2006, highly acidic and $\mathrm{SO}_{4}$-rich vent

36 fluids were collected at both sites and analyzed for the chemical and isotopic composition of major and trace species. Fluids exiting the seafloor have measured temperatures from 48 to $215^{\circ} \mathrm{C}$ and are milky white in appearance due to precipitation of elemental sulfur. Vent fluid concentrations of $\mathrm{Na}, \mathrm{K}, \mathrm{Mg}$, and $\mathrm{Ca}$ are depleted by as much as $30 \%$ relative to seawater, but have the same relative abundance. In contrast, the fluids are highly enriched in dissolved $\mathrm{CO}_{2}$, $\mathrm{Cl}, \mathrm{SiO}_{2(a q)}, \mathrm{Fe}^{2+}$, and $\mathrm{Al}^{3+}$ relative to seawater. Measured $\mathrm{pH}\left(25^{\circ} \mathrm{C}\right)$ ranged from 0.95 to 1.87 and aqueous $\mathrm{SO}_{4}{ }^{2-}$ ranged from 35 to $135 \mathrm{mmol} / \mathrm{kg}$. The chemical and isotopic composition points to formation via subsurface mixing of seawater with a $\mathrm{Na}-, \mathrm{K}-, \mathrm{Mg}$-, and $\mathrm{Ca}-$ free, volatile-rich magmatic fluid exsolved from subsurface magma bodies during a process analogous to subaerial fumarole discharge. Estimates of the magmatic end-member composition indicate a fluid phase where $\mathrm{H}_{2} \mathrm{O}>\mathrm{SO}_{2}>\mathrm{CO}_{2} \approx \mathrm{Cl}>\mathrm{F}$. The hydrogen and oxygen isotopic composition of $\mathrm{H}_{2} \mathrm{O}$ and carbon

47 isotopic composition of $\mathrm{CO}_{2}$ in the vent fluids strongly suggest a contribution of slab-derived

$48 \mathrm{H}_{2} \mathrm{O}$ and $\mathrm{CO}_{2}$ to melts generated in the mantle beneath the Eastern Manus volcanic zone.

49 Abundant magmatically-derived $\mathrm{SO}_{2}$ undergoes disproportionation during cooling in upflow zones and contributes abundant acidity, $\mathrm{SO}_{4}{ }^{2-}$, and $\mathrm{S}^{(0)}(s)$ to the venting fluids. Interaction of these

51 highly acidic fluids with highly altered mineral assemblages in the upflow zone are responsible 52 for extensive mobilization of $\mathrm{SiO}_{2(a q)}, \mathrm{Fe}^{2+}$, and $\mathrm{Al}^{3+}$. Temporal variability in the speciation and

53 abundance of aqueous S species between 1995 and 2006 at the DESMOS vent field suggests an 54 increase in the relative abundance of $\mathrm{SO}_{2}$ in the magmatic end-member that has mixed with 55 seawater in the subsurface. Results of this study constrain processes responsible for the 56 formation of hot-spring fluids in magmatically active back-arc environments and the resulting 57 chemical exchange between the lithosphere and water column. 


\section{INTRODUCTION}

Submarine hot-spring fluids contain abundant magmatic volatiles that can fundamentally infuence fluid-rock reactions and promote chemical exchange between the lithosphere and

63 overlying water column. In back-arc and submarine arc hydrothermal environments, spatial and 64 temporal variability in crustal composition, abundance and composition of magmatic volatiles,

65 subduction and mantle dynamics, magmatic activity, and seafloor morphology result in a broad 66 range of hydrothermal fluid compositions. All of these factors are influenced by the subducting 67 slab and vary systematically with increasing distance from the arc as the depth of subduction 68 increases (Sinton et al., 2003; Pearce and Stern, 2006; Martinez et al., 2006; Bezos et al. 2009; 69 Escrig et al., 2009; Mottl et al., 2011; Reeves et al., 2011). In the Manus back-arc basin, for 70 example, the Vienna Woods hydrothermal system is hosted in basaltic crust where back-arc 71 rifting and crustal generation is fully developed along the Manus spreading center located 250

$72 \mathrm{~km}$ from the New Britain arc. At this location, magmatic volatiles in seawater-derived vent fluids 73 are dominated by $\mathrm{CO}_{2}$ with no evidence for significant $\mathrm{H}_{2} \mathrm{O}$ or $\mathrm{SO}_{2}$ contributions (Reeves et al., 74 2011), similar to mid-ocean ridge settings characterized by basaltic magmatism (Lilley et al. 75 2003; Shanks, 1995). Further to the east at the PACMANUS, DESMOS, and SuSu Knolls 76 hydrothermal areas, hot-springs are hosted in more felsic crust within an extensional transform zone that lacks a clearly-defined spreading center. Located $\leq 100 \mathrm{~km}$ from the active New Britain arc, the influence of the subducting slab on hydrothermal fluid chemistry is readily apparent in the composition of dissolved volatiles. In addition to $\mathrm{CO}_{2}$, magmatic degassing is thought to contribute significant quantities of $\mathrm{H}_{2} \mathrm{O}, \mathrm{SO}_{2}$, and $\mathrm{HF}$ to PACMANUS and DESMOS vent fluids

81 (Gamo et al., 1997; Gena et al., 2006; Reeves et al., 2011). Because $\mathrm{SO}_{2}$ disproportionation to 82 sulfuric acid (Iwasaki and Ozawa, 1960; Kusakabe et al., 2000; Holland, 1965) and direct 83 addition of other acidic magmatic volatiles such as $\mathrm{HCl}$ represent abundant sources of strong 84 acids, magmatic degassing in these environments significantly influences the mineralogy and 85 composition of crustal alteration assemblages and the transport of metals in solution. The contribution of magmatic fluids to hydrothermal fluid chemistry has received much

87 attention in the context of ore-deposit formation (e.g. Hedenquist and Lowenstern, 1994; de 88 Ronde, 1995; Heinrich, 2005; Yang and Scott, 2006). It has been suggested that magmatic fluids may contain levels of magma-derived ore-forming metals that are sufficient to account for the 
90 quantities of metals observed in seafloor mineral deposits and may represent the source of metals

91 in hydrothermal fluids responsible for ore formation (Yang and Scott, 1996; 2002). Magmatic

92 fluids have also been invoked as a source of acidity and complexing ligands to hydrothermal

93 fluids that may efficiently leach ore-forming metals from surrounding crustal rocks prior to

94 concentration at the site of deposition (Hedenquist and Lowenstern, 1994). Recent studies have

95 suggested that acidic magmatic volatiles may contribute to metal mobilization in seawater-

96 derived metal-rich black-smoker fluids venting in arc and back-arc environments (Embley et al.,

97 2006, Resing et al., 2007; Takai et al., 2008; de Ronde et al., 2005; 2011; Mottl, et al., 2011;

98 Reeves et al., 2011). Although these fluids show a clear magmatic contribution, the composition

99 of the magmatic fluid prior to mixing with the convectively circulating seawater-derived

100 component and its role during metal mobilization is obscured by subsequent fluid-rock

101 interaction and phase separation processes.

102 Magmatic volatiles have been identified in highly acidic $\mathrm{SO}_{4}$-rich low temperature white 103 smoker fluids venting from the back-arc DESMOS vent field and the NW Rota-1 and Brothers

104 intraoceanic arc volcanos (Gamo et al., 1997; Gena et al., 2006; Resing et al., 2007; Butterfield

105 et al., 2011; de Ronde et al., 2011). These acid-sulfate fluids represent a very different style of

106 hydrothermal activity compared to high temperature black-smoker fluids that have been studied

107 extensively at oceanic-spreading centers. In particular, they are more acidic and contain

108 substantially higher aqueous $\mathrm{SO}_{4}$ and $\mathrm{Mg}$ concentrations relative to black-smoker fluids, sharing

109 similarities with the fluids responsible for high sulfidation deposits in subaerial settings

110 (Hedenquist and Lowenstern, 1994). While numerous hydrothermal systems with this type of

111 venting are now known to exist in back-arc and intraoceanic arc environments (Gamo et al.

112 1997; Tivey et al. 2006; Butterfield et al. 2011; Leybourne et al., 2012; de Ronde et al. 2011),

113 compositional information is limited and their temporal variability has only been observed

114 indirectly through changes in water column plume chemistry (de Ronde et al., 2003; 2005).

115 Because their chemistry appears to be highly influenced by the abundant presence of magmatic

116 volatiles, they can provide new insight into the composition of magmatic fluids involved in

117 hydrothermal activity in submarine back-arc and arc settings, and their role in hydrothermal

118 alteration and magma dynamics.

119 Here we report data for the composition of acid-sulfate fluids collected in 2006 from the

120 SuSu Knolls and DESMOS vent fields located in the back-arc environment of the Eastern Manus 
121 Basin. The compositions of fluids from the SuSu Knolls vent area have not been reported 122 previously and greatly expand the range of observations that can be used to constrain physical 123 and chemical processes associated with submarine acid-sulfate venting. The DESMOS area was

124 previously sampled on several occasions between 1995 and 2000 (Gamo et al., 2006 and

125 references therein). The data presented here augment these earlier studies by providing additional 126 information regarding the temporal evolution of acid-sulfate venting. Information regarding the 127 abundance of dissolved gases along with non-volatile aqueous species are used to assess the 128 composition of magmatic fluids released from subseafloor magmatic bodies, processes controlling the formation and composition of acid-sulfate fluids in back-arc environments, and resulting chemical exchange between the lithosphere and water column.

\section{GEOLOGIC SETTING}

The Manus Basin (Fig. 1), located in the northeastern Bismarck Sea, is a young (ca. 3.5 Ma) back-arc basin that is rapidly opening at full rates up to $137 \mathrm{~mm} / \mathrm{y}$ (Tregoning, 2002). It is

138 bordered to the north by the presently inactive Manus Trench and to the south by the active New 139 Britain Trench (Taylor, 1979a; Taylor et al., 1994; Lee and Ruellan, 2006). Volcanism

140 associated with basin extension occurs along a series of spreading centers and rifts between three 141 major transform faults (Taylor, 1979a; Taylor et al., 1994; Martinez and Taylor, 1996). Fully142 developed spreading in the center of the basin occurs along the $120 \mathrm{~km}$-long Manus Spreading

143 Center, which hosts the unsedimented Vienna Woods hydrothermal field (Both et al., 1986;

144 Tufar, 1990; Lisitsyn et al., 1993; Reeves et al., 2011) in predominantly MORB-like basalt. In 145 contrast, the eastern Manus Basin between the Djaul and Weitin transform faults is an 146 extensional transform zone within remnant Eocene-Oligocene island-arc crust that is thought to 147 have formed during previous southwestward subduction along the Manus Trench (Binns and 148 Scott, 1993; Binns et al., 2007). Volcanism associated with the incipient rifting of pre-existing 149 intermediate/felsic crust has produced a complex series of en echelon neovolcanic seafloor ridges 150 and domes collectively known as the Eastern Manus volcanic zone (Fig. 1). The composition of 151 these edifices varies from basaltic to rhyodacitic compositions (Binns and Scott, 1993;

152 Kamenetsky et al., 2001; Sinton et al., 2003) and they possess isotopic, major, and trace element 
153 characteristics similar to subaerial volcanoes of the New Britain Arc, indicating strong arc 154 affinities (Sinton et al., 2003; Pearce and Stern, 2006). Due to its proximity to the New Britain 155 Arc $(<100 \mathrm{~km})$, the relative influences of the mantle wedge, subducting slab and remnant arc 156 crust on melt production and volcanism in the Eastern Manus volcanic zone are complex (Sinton 157 et al., 2003; Pearce and Stern, 2006). During the last two decades, areas of hydrothermal activity 158 have been discovered in the Eastern Manus volcanic zone (Fig. 1), including the DESMOS 159 caldera, the SuSu Knolls area, and the PACMANUS and Northeast Pual sites located on Pual

160 Ridge (Binns and Scott, 1993; Gamo et al., 1993, 1997, 2006; Auzende et al., 1997, 2000; Binns 161 et al., 1997; Gena et al., 2001, 2006; Moss and Scott, 2001; Tivey et al., 2006; Hrischeva et al., 162 2007; Craddock et al., 2010; Reeves et al., 2011).

\subsection{Hydrothermal Vent Fields}

\subsubsection{DESMOS Caldera}

The DESMOS neovolcanic edifice is an elongated NNW-trending caldera rising to $\sim 1810$ $\mathrm{m}$ depth with a width of 1.5 to $2 \mathrm{~km}$ and a caldera depression of 150 to $250 \mathrm{~m}$ (Fig. 1b). The seafloor within the caldera consists of fresh basaltic andesite pillow lavas, changing to hyaloclastite deposits of both altered and unaltered basaltic andesite clasts on the northern caldera wall (Gena et al., 2001, 2006; Tivey et al., 2006). In some cases, recent pillow flows cover hyaloclastite talus and, in general, sediment cover is minor to negligible (Tivey et al.,

172 2006). Buoyant hydrothermal plumes discovered in 1990 provided the first evidence for hot173 spring activity at this site (Gamo et al., 1993). In 1995, venting of milky white smoker fluids

$174\left(88-120^{\circ} \mathrm{C}\right)$ at the Onsen site was documented on a ledge of the northern wall (Gamo et al., 175 1997, 2006). The milky white precipitate characteristic of this venting was shown to be 176 elemental sulfur (Gena et al., 2006). Previous studies have collected fluid samples in 1995, 1996, 177 1998, 1999, and 2000 (Auzende et al., 1996, 1997; Gamo et al., 1996b, 1997, 2006; Douville et 178 al., 1999a,b; Gena et al., 2001, 2006; Fourre et al., 2006). Fluids samples were collected during 179 this study at two sites (D1 and D2; Fig. 1) at a depth of $1910 \mathrm{~m}$ from the area of venting that was 180 approximately $30 \mathrm{~m}$ in diameter in 2006. The seafloor expression of hydothermal activity is 181 manifest as poorly focused venting of white smoker fluids at 70 to $117^{\circ} \mathrm{C}$ from small flange-like 182 deposits composed of native sulfur and from sulfur-cemented, highly bleached hyaloclastite talus 183 with a notable absence of sulfide structures or deposits. 


\subsubsection{North $\mathrm{Su}$}

The North Su site (Fig. 1c) is located on a dacitic, neovolcanic dome that rises to a water depth of $1160 \mathrm{~m}$ within the SuSu Knolls series of hydrothermally-active neovolcanic edifices

188 that overlie the older andesitic Tumai Ridge (Binns et al., 1997; Auzende et al., 2000; Moss and 189 Scott, 2001; Tivey et al., 2006; Hrischeva et al., 2007). Unlike DESMOS, no caldera is present 190 on the North Su dome. The entire series of SuSu Knolls edifices is covered with a sediment 191 apron of variable thickness (up to several meters) consisting of layered, dark and locally sulfidic sandy sediment that is most likely a mixture of volcanoclastic and pelagic/hemipelagic material,

193 based on the compositions of adjacent Suzette area sediments investigated by Hrischeva et al.

194 (2007). A large complex of black smokers up to $11 \mathrm{~m}$ high venting fluids with variable

195 temperatures $\leq 325^{\circ} \mathrm{C}$ is present on the summit of the North $\mathrm{Su}$ dome (these fluids are not

196 discussed here). The flanks of the dome host numerous white smoker vents that are very similar

197 in nature to DESMOS, but substantially more abundant and vigorous with temperatures of 48 to

$198215^{\circ} \mathrm{C}$. The white smoker fluids typically vent from talus piles consisting of extensively altered

199 volcanic clasts, but in some cases from areas with minor hydrothermal sediment cover, and flows

200 and flanges of native sulfur are common nearby. In areas of more substantial hydrothermal

201 sediment cover on the dome flanks, molten sulfur at temperatures of 272 to $284{ }^{\circ} \mathrm{C}$ was

202 recovered less than $0.5 \mathrm{~m}$ beneath the sediment-water interface. Several large lava spines

203 protrude up to $15 \mathrm{~m}$ from the hydrothermal detritus and diffuse venting was observed around the 204 base of these structures. Fluids samples were collected from two locations (NS1 and NS2; Fig. 1) 205 at $1160 \mathrm{~m}$ water depth.

\section{METHODS} et al., 2002) and syringe style 'major' samplers (Von Damm et al., 1985) deployed from the

212 ROV Jason II. At each vent, two separate samples were collected using the gas-tight samplers

213 (IGT-prefix, Table 1) and a third sample was collected using the 'major' sampler (M-prefix, 214 Table 1). Vent fluid temperature was monitored continuously during fluid sampling using a 
215 thermocouple attached to the end of the sampler inlet snorkel. The reported temperatures (Table

216 1) represent maximum values recorded during collection of each sample with an estimated

217 uncertainty of $\pm 2{ }^{\circ} \mathrm{C}$.

218 Fluid samples were processed on the ship within $24 \mathrm{~h}$ of recovery. Shipboard

219 measurements of $\mathrm{pH}\left(25^{\circ} \mathrm{C}\right)$ were made using a $\mathrm{Ag} / \mathrm{AgCl}$ combination reference electrode that

220 was calibrated daily. Dissolved $\mathrm{H}_{2}$ and $\mathrm{CH}_{4}$ abundances were determined shipboard following a

221 headspace extraction using a gas chromatograph equipped with a $5 \AA$ molecular sieve packed

222 column and a thermal conductivity detector. Total aqueous sulfide $\left(\Sigma \mathrm{H}_{2} \mathrm{~S}=\mathrm{H}_{2} \mathrm{~S}+\mathrm{HS}^{-}+\mathrm{S}^{2-}\right)$ was

223 sparged from a sample aliquot acidified with $25 \mathrm{wt}$. \% phosphoric acid and precipitated

224 shipboard as $\mathrm{Ag}_{2} \mathrm{~S}$ in a 5 wt. \% solution of $\mathrm{AgNO}_{3}$ for subsequent gravimetric measurement in a

225 shore-based laboratory.

226 For each sample, several aliquots were stored in acid cleaned high density polyethylene

227 bottles for shore-based analysis. One aliquot was sparged at sea for approximately 30 minutes

228 with ultra-high purity $\mathrm{N}_{2}$ gas prior to storage to remove volatile sulfur species such as $\mathrm{H}_{2} \mathrm{~S}$ and

$229 \mathrm{SO}_{2}$ that may oxidize during storage and contribute to the measured total dissolved sulfate

230 concentration $\left(\Sigma \mathrm{SO}_{4}=\mathrm{SO}_{4}{ }^{2-}+\mathrm{HSO}_{4}{ }^{-}+\mathrm{H}_{2} \mathrm{SO}_{4}\right)$. Major anions $\left(\mathrm{Cl}, \Sigma \mathrm{SO}_{4}, \mathrm{Br}, \mathrm{F}\right)$ and cations $(\mathrm{Na}$,

$231 \mathrm{~K}, \mathrm{Ca}, \mathrm{Mg}$ ) were analyzed by ion chromatography with suppressed conductivity detection.

232 Another aliquot was acidified with analytical-grade Optima ${ }^{\circledR} \mathrm{HCl}$ prior to storage for trace metal

233 analysis by inductively-coupled plasma mass spectrometry (ICP-MS) and inductively-coupled

234 plasma atomic emission spectroscopy (ICP-AES). A sub-sample of the acidified aliquot was

235 diluted 100-fold (v/v) at sea for measurement of aqueous $\mathrm{SiO}_{2}$ by ICP-AES. Samples of high

236 temperature vent fluids typically contain transition metal-rich precipitates due to cooling and

237 mixing with alkaline seawater during sampling (e.g. Trefry et al., 1994). These precipitates were

238 collected on $0.45 \mu \mathrm{m}$ nylon filters then dissolved and analyzed by ICP-MS, allowing

239 reconstruction of fluid composition prior to precipitation. Several aliquots of fluid were stored in

$24030 \mathrm{~mL}$ culture tubes with butyl-rubber stoppers for shore-based chemical and isotopic analysis of

241 total dissolved carbonate $\left(\Sigma \mathrm{CO}_{2}=\mathrm{CO}_{3}{ }^{2-}+\mathrm{HCO}_{3}{ }^{-}+\mathrm{H}_{2} \mathrm{CO}_{3}\right)$. Concentrations of dissolved $\Sigma \mathrm{CO}_{2}$

242 were determined after acidification of fluids with $25 \mathrm{wt}$ \% phosphoric acid by injecting aliquots

243 of headspace gas directly into a gas chromatogaph equipped with a Porapak-Q packed column

244 and a thermal conductivity detector. These data were corrected to account for $\mathrm{CO}_{2}$ partitioning

245 between the headspace and fluid phase within the culture tube. Fluid aliquots were also flame- 
sealed in glass ampoules for stable hydrogen and oxygen isotope analysis. Estimates of overall maximum analytical uncertainties $(2 \sigma)$ are $\pm 10 \%$ for $\mathrm{H}_{2}, \mathrm{CH}_{4}, \mathrm{CO}, \Sigma \mathrm{H}_{2} \mathrm{~S}, \mathrm{Sr}, \mathrm{Li}, \mathrm{Rb}, \mathrm{Cs}, \mathrm{Fe}$, and Al concentrations, $\pm 5 \%$ for $\Sigma \mathrm{CO}_{2}, \mathrm{Mn}, \mathrm{Br}$, and $\mathrm{F}$ concentrations, $\pm 3 \%$ for $\mathrm{Na}, \mathrm{Cl}, \mathrm{Ca}$, K, and $\mathrm{SO}_{4}$ concentrations, $\pm 2 \%$ for $\mathrm{SiO}_{2}$ and $\mathrm{B}$ concentrations, and \pm 0.02 units for $\mathrm{pH}\left(25^{\circ} \mathrm{C}\right)$.

The stable carbon isotope composition of $\Sigma \mathrm{CO}_{2}$ was determined by isotope ratio monitoring - gas chromatography mass spectrometry (irm-GCMS) using a Finnigan Delta ${ }^{\text {Plus }}$ XL mass spectrometer coupled to an Agilent 6890 gas chromatograph via a GCCIII combustion

253 interface held at $950{ }^{\circ} \mathrm{C}$ with a constant oxygen trickle. The pooled standard deviation $(1 \sigma)$ for

$254 \delta^{13} \mathrm{C}_{\mathrm{CO} 2}$ measurements is $0.3 \%$. The ${ }^{34} \mathrm{~S}$ content of $\mathrm{SO}_{4}$ in selected sparged fluid samples was

255 determined using an automated elemental analyzer interfaced to an isotope ratio mass

256 spectrometer following precipitation as $\mathrm{BaSO}_{4}$. Analytical uncertainty for $\delta^{34} \mathrm{~S}$ values was \pm 0.3

$257 \%(2 \sigma)$. Oxygen isotope compositions of vent fluid $\mathrm{H}_{2} \mathrm{O}$ were analyzed using an automated $\mathrm{CO}_{2}$

258 equilibration device on a VG Optima mass spectrometer. Hydrogen isotope compositions of vent 259 fluid $\mathrm{H}_{2} \mathrm{O}$ were analyzed as $\mathrm{H}_{2}$ on a Finnigan MAT 252 mass spectrometer. The Zn reduction 260 technique (Kendall and Coplen, 1985) was used to prepare $\mathrm{H}_{2}$ following salt removal by vacuum distillation. Analytical uncertainty $(2 \sigma)$ for $\delta \mathrm{D}_{\mathrm{H} 2 \mathrm{O}}$ and $\delta^{18} \mathrm{O}_{\mathrm{H} 2 \mathrm{O}}$ values were estimated to be $3 \%$ and $0.2 \%$, respectively. ${ }^{87} \mathrm{Sr} /{ }^{86} \mathrm{Sr}$ ratios were determined on a subset of samples on a Finnigan

263 MAT 261 thermal ionization mass spectrometer using static multi-collection (additional details in Eickmann et al., 2009). Analytical uncertainty for ${ }^{87} \mathrm{Sr} /{ }^{86} \mathrm{Sr}$ values is estimated at $0.00007(2 \sigma)$ based on three individually processed aliquots of IAPSO reference seawater. With the exception of ${ }^{87} \mathrm{Sr} /{ }^{86} \mathrm{Sr}$, all stable isotope data are reported using standard delta notation. For the isotope $A$ of interest, $\delta A$ is defined by the expression:

$$
\delta A(\%)=\left[\frac{R_{S}-R_{S T D}}{R_{S T D}}\right] \times 1000
$$

271 where $R_{S}$ and $R_{S T D}$ are the isotope ratios of the sample and standard, respectively. $\delta^{13} \mathrm{C}_{\mathrm{CO} 2}$ and

$272 \delta^{34} \mathrm{~S}_{\mathrm{SO} 4}$ are expressed relative to the V-PDB and V-CDT scales, respectively, whereas $\delta^{18} \mathrm{O}_{\mathrm{H} 2 \mathrm{O}}$ 273 and $\delta \mathrm{D}_{\mathrm{H} 2 \mathrm{O}}$ values are expressed relative to the V-SMOW scale. 


\subsection{Major Species and $\mathrm{pH}$}

In general, acid-sulfate fluids at DESMOS and North Su contain high levels of Mg that range from just below seawater concentrations to a minimum value of $39.2 \mathrm{mmol} / \mathrm{kg}$ in the NS2 vent fluid. Replicate samples from each vent yielded similar concentrations and temperatures indicating that the elevated $\mathrm{Mg}$ abundances reflect the composition of fluids exiting the seafloor rather than inadvertent entrainment of ambient seawater during sampling.

A striking feature of these fluids that is reflected in the term "acid-sulfate" is the extraordinarily low measured $\mathrm{pH}\left(25^{\circ} \mathrm{C}\right)$ and elevated $\Sigma \mathrm{SO}_{4}$ concentrations (Table 1). Measured $\mathrm{pH}\left(25^{\circ} \mathrm{C}\right)$ values vary from 0.95 to 1.41 at DESMOS and 0.87 to 1.85 at North Su. These are amongst the lowest values of $\mathrm{pH}$ measured to date in seafloor hydrothermal systems. The low $\mathrm{pH}$ values are accompanied by measured $\Sigma \mathrm{SO}_{4}$ abundances far in excess of seawater concentrations, varying from 54.4 to $125 \mathrm{mmol} / \mathrm{kg}$ at DESMOS and 35.3 to $132 \mathrm{mmol} / \mathrm{kg}$ at North Su. Measurement of aqueous $\Sigma \mathrm{SO}_{4}$ in fluid aliquots that were not $\mathrm{N}_{2}$-sparged at sea reveals concentrations that are higher by as much as $22 \mathrm{mmol} / \mathrm{kg}$ (Table 1 ). These higher concentrations cannot reflect $\mathrm{H}_{2} \mathrm{~S}$ oxidation during storage due to the very low $\Sigma \mathrm{H}_{2} \mathrm{~S}$ contents of these fluids (Table 1). It is likely that the excess $\mathrm{\Sigma SO}_{4}$ concentrations measured in the non-sparged aliquots reflect oxidation of residual $\mathrm{SO}_{2}$ and other associated intermediate oxidation state sulfur species (e.g. thiosulfate, $\mathrm{S}_{2} \mathrm{O}_{3}{ }^{-}$, Kusakabe et al., 2000) during the storage period of several months and the rapid kinetics of $\mathrm{SO}_{2(\text { aq) }}$ oxidation at low $\mathrm{pH}$ in $\mathrm{Fe}$ - and $\mathrm{Mn}$-bearing solutions (Huss et al., 1982). Assuming this to be the case, the abundance of $\mathrm{SO}_{2}$ and associated species can be calculated from the difference in measured $\Sigma \mathrm{SO}_{4}$ concentrations between the sparged and nonsparged samples. $\mathrm{SO}_{2}$ concentrations estimated in this way vary from 3 to $22 \mathrm{mmol} / \mathrm{kg}$ (Table 1 ). These represent minimum values since no measures were taken to minimize degassing of volatile species during handling of the unsparged fluid aliquots.

Measured $\mathrm{Cl}$ concentrations in DESMOS and North Su acid-sulfate fluids are consistently depleted relative to seawater, varying from 492 to $523 \mathrm{mmol} / \mathrm{kg}$ at DESMOS and 304443 to $527 \mathrm{mmol} / \mathrm{kg}$ at North Su. Similar depletions are observed in the measured $\mathrm{Na}$ concentrations that vary from 391 to $419 \mathrm{mmol} / \mathrm{kg}$ at DESMOS and 340 to $453 \mathrm{mmol} / \mathrm{kg}$ at North $\mathrm{Su}$. Unlike the majority of ridge-crest hydrothermal fluids that are enriched in K relative to 
seawater (Von Damm, 1995; German and Von Damm, 2003), the DESMOS and North Su K

308 concentrations show depletions at levels similar to that observed for $\mathrm{Na}$ and $\mathrm{Cl}$, with

309 concentrations ranging from 7.8 to $10 \mathrm{mmol} / \mathrm{kg}$. Measured Ca concentrations, however, are

310 characterized by both minor depletions and enrichments, varying from 8.9 to $12 \mathrm{mmol} / \mathrm{kg}$.

311 Aqueous $\mathrm{SiO}_{2}$ concentrations are highly enriched in the acid-sulfate fluids relative to seawater

312 varying from 3.0 to $9.9 \mathrm{mmol} / \mathrm{kg}$.

\subsection{Trace Elements}

Measured concentrations of the alkali trace elements $\mathrm{Li}, \mathrm{Rb}$, and $\mathrm{Cs}$ in acid-sulfate fluids at DESMOS and SuSu Knolls are enriched relative to seawater (Table 1). Aqueous Cs concentrations show the greatest enrichment, varying from 8 to $64 \mathrm{nmol} / \mathrm{kg}$ relative to 2.3 $\mathrm{nmol} / \mathrm{kg}$ in seawater, while $\mathrm{Li}$ and $\mathrm{Rb}$ show concentrations that are only slightly enriched or depleted relative to the seawater values of 28 and $1.3 \mu \mathrm{mol} / \mathrm{kg}$, respectively. Measured B concentrations, however, are substantially depleted relative to the seawater concentration of 426 $\mu \mathrm{mol} / \mathrm{kg}$, varying from 157 to $194 \mu \mathrm{mol} / \mathrm{kg}$ (Table 1 ).

Measured concentrations of $\mathrm{Br}$ are below seawater values (Table 1). Although the measured concentrations of aqueous $\mathrm{Br}$ correlate with aqueous $\mathrm{Cl}, \mathrm{Br} / \mathrm{Cl}$ ratios are at or below seawater values. Measured aqueous $\mathrm{F}$ concentrations show highly variable behavior, being depleted relative to seawater ( $64 \mu \mathrm{mol} / \mathrm{kg})$ in the D2 and NS1 fluids with concentrations of 4 to 8 $\mu \mathrm{mol} / \mathrm{kg}$ and 46 to $55 \mu \mathrm{mol} / \mathrm{kg}$, respectively, while the D1 and NS2 fluids show enriched F concentrations of 85 to $137 \mu \mathrm{mol} / \mathrm{kg}$ and 90 to $128 \mu \mathrm{mol} / \mathrm{kg}$, respectively.

Dissolved Fe concentrations in the acid-sulfate fluids vary from 5.46 to $12.4 \mathrm{mmol} / \mathrm{kg}$ at DESMOS and 1.32 to $3.10 \mathrm{mmol} / \mathrm{kg}$ at North $\mathrm{Su}$. The high Fe concentrations are accompanied by high aqueous $\mathrm{Al}$ concentrations that vary from 0.209 to $1.64 \mathrm{mmol} / \mathrm{kg}$ at DESMOS and 0.180 to $1.08 \mathrm{mmol} / \mathrm{kg}$ at North $\mathrm{Su}$. The high aqueous Fe and $\mathrm{Al}$ concentrations, notwithstanding, $\mathrm{Mn}$ concentrations are substantially lower, ranging from 28 to $46 \mu \mathrm{mol} / \mathrm{kg}$ at DESMOS and 21 to 81 $\mu \mathrm{mol} / \mathrm{kg}$ at North Su.

\subsection{Dissolved Gases}

DESMOS and North Su acid-sulfate fluids are characterized by measured $\mathrm{H}_{2}$ concentrations that vary from 1.7 to $22 \mu \mathrm{mol} / \mathrm{L}$ (Table 1). The elevated $\mathrm{H}_{2}$ concentrations are 
accompanied by dissolved $\Sigma \mathrm{H}_{2} \mathrm{~S}$ concentrations that vary from below detection $(<0.002$ $\mathrm{mmol} / \mathrm{kg}$ ) to $0.63 \mathrm{mmol} / \mathrm{L}$. Measured dissolved $\mathrm{CO}_{2}$ concentrations vary from 11 to $23 \mathrm{mmol} / \mathrm{kg}$ in the acid-sulfate fluids, while concentrations of dissolved $\mathrm{CH}_{4}$ vary from 0.02 to $0.64 \mu \mathrm{mol} / \mathrm{L}$.

\section{4 $\mathrm{H}_{2} \mathrm{O}, \mathrm{CO}_{2}$ and $\mathrm{SO}_{4}$ isotopic composition}

The isotopic composition of hydrogen and oxygen in $\mathrm{H}_{2} \mathrm{O}$, carbon in $\mathrm{CO}_{2}$, and sulfur in $\Sigma \mathrm{SO}_{4}$ from the DESMOS and North Su fluids show substantial deviations from seawater values (Table 1). For $\mathrm{H}_{2} \mathrm{O}$, measured values of $\delta^{18} \mathrm{O}$ vary from 0.2 to $2.2 \%$ while values of $\delta \mathrm{D}$ vary from -1 to $-8 \%$. The measured carbon isotopic composition of $\Sigma \mathrm{CO}_{2}$ ranges from -2.4 to -3.6 \%. Measured $\delta^{34} \mathrm{~S}$ values for dissolved $\mathrm{SO}_{4}$ are much lower than seawater $(+20.99 \%$, Rees et al., 1978), ranging from +9.8 to $+17.2 \%$.

\section{DISCUSSION}

Many aspects of the acid-sulfate fluid compositions in the Eastern Manus Basin show a resemblance to the composition of seawater, while other aspects are dramatically different. For example, abundances of $\mathrm{Na}, \mathrm{K}, \mathrm{Mg}, \mathrm{Cl}$ and some trace alkalis show consistent small depletions relative to seawater concentrations, while acidity, $\mathrm{SO}_{4}, \mathrm{CO}_{2}, \mathrm{H}_{2}, \mathrm{Fe}, \mathrm{Mn}$, and $\mathrm{Al}$ abundances are substantially enriched. Models for the formation and chemical evolution of black-smoker vent fluids observed at oceanic-spreading centers involve the convective circulation of seawater in the oceanic lithosphere. Conductive heating of seawater as it percolates downwards through permeable crustal pathways induces extensive chemical interaction with fresh rock at low water/rock ratios and, in many cases, phase separation that extensively modify the original seawater composition (Seyfried, 1987; Von Damm 1995; Butterfield et al., 2003; German and Von Damm, 2003). The integrated effects of these processes produce fluids that are depleted in

$364 \mathrm{Mg}$ and $\mathrm{SO}_{4}$, moderately acidic ( $\mathrm{pH} \approx 3$ to 4 ), and enriched in $\mathrm{Ca}, \mathrm{K}, \mathrm{SiO}_{2}$, mobile trace 365 elements, $\mathrm{H}_{2}, \mathrm{H}_{2} \mathrm{~S}, \mathrm{CO}_{2}$, and sulfide-forming metals that ultimately vent at the seafloor at temperatures approaching $400{ }^{\circ} \mathrm{C}$ (Seyfried, 1987; Von Damm 1995; German and Von Damm,

367 2003). The low temperatures and compositionally distinct nature of acid-sulfate fluids at

368 DESMOS and SuSu Knolls strongly suggest that a fundamentally different model is necessary to 369 explain their genesis. Here we present evidence that formation of these fluids does not involve 
thermal convection of seawater-derived hydrothermal fluids, but instead occurs via direct injection of aqueous and sulfurous magmatic fluids directly into seawater, and thus represents a submarine analog of subaerial fumaroles.

\subsection{Origin of Acid Sulfate Fluids}

Considering the high porosity and permeability of shallow oceanic crust and the ubiquitous occurrence of seawater in submarine environments, the involvement of chemically unmodified seawater in the formation of acid-sulfate fluids at DESMOS and North Su is not surprising. In addition to concentrations of $\mathrm{Na}, \mathrm{K}$, and $\mathrm{Mg}$ that are at, or slightly below, seawater values, relative abundances of these species are similar to seawater, regardless of their absolute concentration. For example, molal $\mathrm{Na} / \mathrm{K}, \mathrm{K} / \mathrm{Mg}$, and $\mathrm{Na} / \mathrm{Mg}$ ratios in the DESMOS and North $\mathrm{Su}$ fluids vary from 45 to $48,0.18$ to 0.20 , and 8.5 to 9.0 and are, within analytical error, nearly identical to seawater values of 48, 0.19, and 9.0. This relationship is apparent in Figure 2 where $\mathrm{Na}$ and $\mathrm{K}$ reveal a linear relationship that is consistent with a line drawn between seawater composition and the origin when plotted against $\mathrm{Mg}$. These trends indicate that the extent of depletion for each species in a given fluid is the same relative to seawater and is consistent with their conservative behavior during seawater dilution by an aqueous fluid containing near zero concentrations of $\mathrm{Na}, \mathrm{K}$, and $\mathrm{Mg}$. Although the possibility exists that mixing could involve a non-seawater fluid containing significant, but lower than seawater, concentrations of $\mathrm{Na}, \mathrm{K}$, and $\mathrm{Mg}$, this scenario is unlikely since it would require that the relative abundances of all three species in the more dilute fluid were identical to seawater.

$392 \mathrm{Mg}$ is a water-rich volatile phase degassing from an underlying magma chamber. Volumetrically 393 significant, low salinity, volatile rich magmatic fluids are predicted to form along with lesser 394 volumes of high salinity brines during supercritical phase separation of $\mathrm{NaCl}$-rich magmatic 395 fluids released at magmatic temperatures and ambient pressures in the vicinity of shallow magma 396 chambers (Gruen et al., 2014). Due to the lower density of the low salinity fluids relative to the 397 higher density brines and seawater, they preferentially vent at the seafloor (Gruen et al., 2014). 398 Thus, in contrast to processes responsible for the formation of black-smoker fluids, the model 399 proposed here involves a high temperature endmember fluid that is entirely magmatic in origin 400 and not the result of extensive chemical interaction between seawater and fresh rock during 
thermally driven convective circulation through oceanic crust. The formation of such fluids has

402 been predicted by hydrodynamic models for hydrothermal activity in the vicinity of volatile-rich

403 silicic magmas associated with arc-volcanism (Gruen et al., 2014). Reaction of magmatic fluids

404 with crustal rocks during ascent before and after mixing with cold seawater may affect the

405 abundance of some chemical species while leaving others unchanged. Based on the minimum

406 measured $\mathrm{Mg}$ concentrations at each vent and the assumption of conservative mixing of a zero-

$407 \mathrm{Mg}$ magmatic fluid and seawater, the NS1, NS2, D1, and D2 fluids contain 5.3, 25.2, 14.3, and

4086.1 wt. \% magmatic fluid, respectively.

409 Preservation of seawater $\mathrm{Na}: \mathrm{K}: \mathrm{Mg}$ ratios during mixing of magmatic fluid and seawater

410 implies that the source of these elements is predominantly seawater and that chemical exchange

411 of $\mathrm{Na}, \mathrm{K}$, and $\mathrm{Mg}$ with the crust is not occurring to a significant extent before or after mixing.

412 This contrasts with previous interpretations that the elevated $\mathrm{Mg}$ in DESMOS fluids is derived

413 from Mg-silicate dissolution (Gamo et al. 1997). The lack of chemical exchange involving $\mathrm{Na}$,

$414 \mathrm{~K}$, and $\mathrm{Mg}$ should not be interpreted as an indication that fluid-rock reaction is not occurring in

415 subsurface environments responsible for the formation of the acid-sulfate fluids. Indeed,

416 measured concentrations of aqueous $\mathrm{Fe}, \mathrm{Al}$, and $\mathrm{SiO}_{2}$ that approach several $\mathrm{mmol} / \mathrm{kg}$ (Table 1)

417 provide strong evidence for dissolution of Fe-, $\mathrm{Al}$-, and $\mathrm{Si}$-bearing mineral assemblages in

418 response to the high acidity of these fluids. The conservative behavior of $\mathrm{Na}, \mathrm{K}$, and $\mathrm{Mg}$ may

419 reflect the presence of a mineral assemblage depleted in $\mathrm{Na}, \mathrm{K}$, and $\mathrm{Mg}$ in upflow zones, or

420 alternatively, equilibrium between the upflow zone mineral assemblage and the acid-sulfate

421 fluids. Hydrothermal alteration of the oceanic crust in upflow zones typically occurs under fluid-

422 dominated conditions resulting in an alteration rock chemistry and mineralogy dictated by fluid

423 composition. Once equilibrium with a mixed fluid containing relative abundances of $\mathrm{Na}, \mathrm{K}$, and

$424 \mathrm{Mg}$ inherited from seawater has been established, continued fluid flow at constant temperature

425 and pressure will not result in net additional exchange of these elements. Mineral assemblages at

426 DESMOS and the nearby PACMANUS hydrothermal systems, which are interpreted to have

427 formed during advanced argillic alteration by acid-sulfate fluids, typically contain Na- and K-

428 bearing alunite solid solutions, pyrophyllite, silica phases, anhydrite and pyrite, but no $\mathrm{Mg}$ -

429 bearing minerals (Gena et a., 2001; Lackschewitz et al., 2004; Paulick and Bach, 2006; Binns et

430 al., 2007; Hrischeva et al., 2007). The presence of alunite solid solutions containing Na and K

431 and the general absence of Mg-bearing minerals in acid-sulfate alteration assemblages at 
432 DESMOS and SuSu Knolls suggests that the apparent lack of $\mathrm{Na}$ and $\mathrm{K}$ exchange in the acid433 sulfate fluids may reflect fluid-mineral equilibria with highly altered crust, while the lack of $\mathrm{Mg}$ 434 exchange may reflect undersaturation of acid-sulfate fluids with respect to Mg-bearing minerals 435 and their absence in upflow zones.

436 Limited Mn enrichment in the acid-sulfate fluids relative to dissolved Fe (Table 1)

437 provides further support for interaction with highly altered rock in subsurface environments. Mn 438 typically exhibits pH-dependent aqueous mobility similar to Fe (Seewald and Seyfried, 1990), 439 but would be rapidly exhausted during hydrothermal alteration at high water/rock ratios due to its 440 substantially lower concentration relative to Fe in basaltic and felsic crust of the Eastern Manus 441 volcanic zone (Sinton et al., 2003). Limited Mn mobility is also consistent with the relatively 442 minor enrichments of the mobile elements $\mathrm{Li}, \mathrm{Rb}, \mathrm{Cs}$, and $\mathrm{B}$ that would also be rapidly depleted 443 in highly altered rock under fluid-dominated conditions (high water/rock ratio). Thus, a 444 fundamental difference between fluid-rock interaction responsible for the formation of acid445 sulfate and black smoker fluids is that the former involves rocks that have been altered at very 446 high integrated water/rock ratios, while the latter involves interaction with fresh crustal rocks at 447 low water/rock ratios(Seyfried, 1987; Von Damm 1995).

448 The influence of fluid-rock interaction on fluid composition during upflow can be 449 assessed by examining the saturation state of venting fluids with mineral assemblages likely to 450 exist beneath the seafloor. For this purpose, the fluid speciation and reaction path program 451 EQ3NR/EQ6 version 8.0 (Wolery, 1992) was used to calculate the equilibrium distribution of 452 aqueous species at the measured vent temperatures. The supporting thermodynamic database for 453 these calculations was generated at 25 MPa using SUPCRT92 (Johnson et al., 1992) software 454 that included thermodynamic data for minerals (Helgeson et al., 1978) and relevant aqueous 455 inorganic species (Shock and Helgeson, 1988; Shock et al., 1989, 1997; Sverjensky et al., 1997).

456 Thermodynamic properties for $\mathrm{Al}^{3+}$ and aqueous aluminum complexes in the SUPCRT92 457 database were updated with values from Tagirov and Schott (2001). During these calculations, 458 redox equilibrium between aqueous sulfur species was suppressed so that that measured $\Sigma \mathrm{H}_{2} \mathrm{~S}$ 459 and $\Sigma \mathrm{SO}_{4}$ concentrations $\left(25^{\circ} \mathrm{C}\right)$ reflect in situ abundances. This assumption is supported by 460 sluggish reaction kinetics for sulfide-sulfate equilibrium at $25^{\circ} \mathrm{C}$ (Ohmoto and Lasaga, 1982) 461 and the rapid cooling and processing of samples after collection. Activity coefficients for 462 charged aqueous species were calculated using the B-dot equation (Helgeson et al., 1981). 
Results of equilibrium speciation calculations indicate that the acid-sulfate fluids are slightly undersaturated with respect to anhydrite (Fig. 3). In general, the degree of undersaturation decreases in the higher temperature fluids, consistent with the retrograde solubility of anhydrite (Holland and Malinin, 1979). Accordingly, there is a thermodynamic drive for anhydrite dissolution in subsurface environments by the relatively low temperature acid-sulfate fluids sampled at North Su and DESMOS. Fluid compositions that are below anhydrite saturation suggest that there is insufficient time for anhydrite dissolution to reach equilibrium or anhydrite is absent in some subsurface mixing environments. decreasing anhydrite solubility at higher temperatures, suggests that the initial mixing of a $\sim 1000^{\circ} \mathrm{C} \mathrm{SO}_{4}$-rich magmatic volatile phase with $\mathrm{Ca}$-bearing seawater likely results in extensive

474 precipitation of anhydrite and removal of $\mathrm{Ca}$ and $\mathrm{SO}_{4}$ from solution in equimolar amounts.

475 Observed Ca concentrations in acid-sulfate fluids at DESMOS and North Su that are above and 476 below values expected for mixing of pristine seawater with a Ca-free magmatic fluid (Fig. 2) are 477 consistent with both high temperature precipitation and low temperature dissolution.

The speciation calculations also indicate that the acid-sulfate fluids are undersaturated with respect to K-alunite and pyrophyllite (Fig. 3), the Al-bearing minerals likely to exist in regions of the crust extensively altered by highly-acidic and $\mathrm{SO}_{4}$-rich fluids. As is the case for anhydrite, this creates a thermodynamic drive for dissolution of these minerals if present, and the release of $\mathrm{K}, \mathrm{Al}, \mathrm{Si}$, and $\mathrm{SO}_{4}$ to solution. The departure from equilibrium with these phases likely reflects decreasing reaction rates with decreasing temperature as the degree of subsurface mixing increases, and/or the possible absence of these minerals in the subsurface.

The composition of acid-sulfate fluids sampled at DESMOS and North Su in 2006 point to an absence of significant chemical exchange involving dissolved $\mathrm{Na}, \mathrm{K}$, and $\mathrm{Mg}$ during 488 however, since spatial and temporal variability in the release of magmatic volatiles, volcanic/magmatic activity, and crustal fracturing that may expose fresh or less altered rocks to ascending fluids. Reaction with fresh and/or less altered rocks likely results in some chemical exchange of $\mathrm{Na}, \mathrm{K}$, and $\mathrm{Mg}$. Accordingly, the minor departure of $\mathrm{Na}, \mathrm{K}$, and $\mathrm{Mg}$ concentrations in the 1995 fluids (Gamo et al., 2007) relative to trends predicted for conservative mixing of a magmatic volatile and unmodified seawater for the DESMOS fluids in 1995 (Fig. 2) suggests the 
494 involvement of less altered rock during this earlier phase of hydrothermal activity. Similar minor

495 enrichments of $\mathrm{Na}, \mathrm{K}$, and $\mathrm{Mg}$ were observed in acid-sulfate fluids at the Brothers intraoceanic

496 arc volcano (de Ronde et al., 2011). The magnitude of these enrichments/depletions in Na, K,

497 and $\mathrm{Mg}$ are small, however, suggesting that fresh rock is not abundantly present along fluid flow 498 paths.

\subsubsection{Magmatic Volatiles}

The composition of acid-sulfate fluids in the Eastern Manus Basin provides compelling evidence for a magmatic contribution of acidic volatile species to mixed fluids venting at the seafloor. In addition to abundant water and near zero $\mathrm{Na}, \mathrm{K}$, and $\mathrm{Mg}$ concentrations, fluids exsolving from silicic magma in near-arc environments such as SuSu Knolls and DESMOS are also expected to contain abundant volatiles such as $\mathrm{SO}_{2}, \mathrm{HCl}, \mathrm{HF}$, and $\mathrm{CO}_{2}($ Carroll and Webster, 1994; Yang and Scott, 2006). Degassing of $\mathrm{SO}_{2}$ reflects a fundamental difference in the speciation of total $\mathrm{S}$ in back-arc/arc magmas relative to mid-ocean ridge settings, where total $\mathrm{S}$ in MORB melts is predominantly present as sulfide (Carroll and Rutherford, 1988; Carroll and Webster, 1994). Magmatic $\mathrm{SO}_{2}$ strongly partitions into aqueous fluids exsolved from magmas (Scaillet and Pichavant, 2003) and undergoes disproportionation to produce reduced and oxidized sulfur species upon cooling according to the reactions:

While this process is generally assumed to occur below approximately $400{ }^{\circ} \mathrm{C}$, the relative importance of reactions (1) and (2) is strongly dependent on temperature, redox state, $\mathrm{pH}$, and

518 total sulfur (i.e. initial $\mathrm{SO}_{2}$ ) present (Iwasaki and Ozawa, 1960; Kusakabe et al., 2000; Holland,

519 1965; Drummond, 1981). As proposed by Gamo et al. (1997) for DESMOS fluids, this process 520 provides an explanation for the elevated concentrations of $\mathrm{SO}_{4}$ and anomalously low $\delta^{34} \mathrm{~S}_{\mathrm{SO} 4}$ 521 values in acid-sulfate fluids relative to seawater (Table 1). Sulfuric acid produced by reactions 522 (1) and (2), along with $\mathrm{HCl}$ and $\mathrm{HF}$ already present in a volatile magmatic phase, will greatly 523 increase the acidity of the mixed fluid, thereby influencing rock alteration processes and its 
524 ability to transport sulfide mineral forming metals such as $\mathrm{Fe}, \mathrm{Cu}$, and $\mathrm{Zn}$ due to increases in 525 their aqueous solubility.

If it is assumed that these magmatic fluids contain near-zero concentrations of $\mathrm{Na}, \mathrm{K}$, and

$527 \mathrm{Mg}$ prior to mixing with seawater, the same approach used to determine the end-member

528 composition of black smoker fluids (Von Damm et al., 1985) can be used to estimate the endmember composition of the magmatic fluid. Although extrapolation to zero-Na, $-\mathrm{K}$, or -Mg could

530 be used for this purpose, we have opted to use Mg because it is more likely to behave

531 conservatively in acid-sulfate upflow zones due to the limited presence of Mg-bearing minerals

532 in highly altered hydrothermal upflow zones in general (Alt and Bach, 2003) and the highly

533 altered rocks associated with DESMOS venting (Gena et al., 2001), in particular. Results of

534 these extrapolations (Fig. 4, Table 2) yield end-member magmatic fluid concentrations for $\Sigma \mathrm{SO}_{4}$

535 and residual $\mathrm{SO}_{2}$ that vary from 205 to $710 \mathrm{mmol} / \mathrm{kg}$ and 58 to $131 \mathrm{mmol} / \mathrm{kg}$, respectively.

536 Collectively, these concentrations suggest that the initial $\mathrm{SO}_{2}$ content of the magmatic fluid end-

537 member prior to disproportionation ranges from 0.39 to $1.2 \mathrm{~mol} / \mathrm{kg}$ if it is assumed that reaction

538 (2) is the primary pathway for $\mathrm{SO}_{2}$ disproportionation (Table 2). The lack of substantial

539 dissolved $\mathrm{\Sigma}_{2} \mathrm{~S}$, which in some cases was below detection (Table 2), and the abundance of

540 particulate elemental sulfur $\left(\mathrm{S}^{(0)}\right)$ either as 'white smoke' or in molten deposits surrounding the

541 vents, implicate reaction (2) as the dominant mechanism of disproportionation in both the

542 DESMOS and North Su acid-sulfate fluids in 2006.

543 The speciation of sulfur during disproportionation is strongly influenced by in situ $\mathrm{pH}$,

544 dissolved $\mathrm{H}_{2}$, and temperature (Fig. 5). A likely explanation for the predominance of reaction (2)

545 at DESMOS and North $\mathrm{Su}$ is the high initial $\mathrm{SO}_{2}$ content of the magmatic fluids involved. At

546 total $\mathrm{S}$ concentrations similar to the initial $\mathrm{SO}_{2}$ content of the D1 vent $(1.2 \mathrm{~mol} / \mathrm{kg})$,

547 disproportionation between 300 and $400{ }^{\circ} \mathrm{C}$ occurs primarily via reaction (2) and does not

548 produce $\mathrm{H}_{2} \mathrm{~S}$ due to the large stability field of elemental $\mathrm{S}^{(0)}$ (Figs. 5a and b). Below $300^{\circ} \mathrm{C}, \mathrm{SO}_{2}$

549 is increasingly unstable. The presence of minor quantities of $\Sigma \mathrm{H}_{2} \mathrm{~S}$ and abundant elemental $\mathrm{S}^{(0)}$

550 (white smoke) in vents D2 and NS1, in contrast, is likely a result of the lower initial $\mathrm{SO}_{2}$ in these

551 vents relative to D1 and NS2. Under such conditions, it is possible for disproportionation to

552 initially occur by reaction (1) at higher temperatures, producing $\mathrm{H}_{2} \mathrm{~S}$ (Fig. 5c), but as magmatic

553 fluids cool further during mixing, reaction (2) becomes increasingly more important (Fig. 5d).

554 The occurrence of both mechanisms as a function of total S and temperature would also account 
555 for the presence of $\mathrm{H}_{2} \mathrm{~S}$ as well as particulate $\mathrm{S}^{(0)}$ and $\mathrm{HSO}_{4}{ }^{-}$in these fluids, as opposed to only 556 the latter two products of disproportionation in vents D1 and NS2 (Table 2).

The low $\mathrm{H}_{2}$ contents of the acid-sulfate fluids ( 1.7 to $22 \mu \mathrm{mol} / \mathrm{L}$ ) relative to black smoker fluids from back-arc and mid-ocean ridge environments (Charlou et al., 2000; 2002; Lilley et al., 2003; Seewald et al., 2003; Reeves et al., 2011; Pester et al., 2012) are also broadly consistent with the range of redox conditions expected for disproportionation under scenarios similar to those illustrated in Figure 5. It is likely that the speciation of magmatic sulfur plays an important role in regulating dissolved $\mathrm{H}_{2}$ concentrations in these fluids. In subaerial volcanic systems, magmatic $\mathrm{H}_{2}$ and/or hydrothermal alteration of unaltered Fe-bearing rocks in volcanic vent conduits can contribute $\mathrm{H}_{2}$ to hydrothermal fluids that may react with $\mathrm{SO}_{2}$ to form $\mathrm{H}_{2} \mathrm{~S}$ under high temperature conditions. Consumption of $\mathrm{H}_{2}$ by this mechanism may lead to redox buffering of the fluids by the $\mathrm{SO}_{2} / \mathrm{H}_{2} \mathrm{~S}$ couple (Taylor, 1986; Giggenbach, 1997). However, the lack of substantial $\mathrm{H}_{2}$ or $\Sigma \mathrm{H}_{2} \mathrm{~S}$ in the fluids and the highly altered nature of mineral assemblages in the upflow zones at DESMOS and North Su suggest that disproportionation alone dominates the fate of $\mathrm{SO}_{2}$ and fluid/rock reactions in hydrologic conduits have a minimal influence on the redox state of venting fluids at these locations.

Owing to the coexistence of relatively high $\Sigma \mathrm{SO}_{4}$ concentrations with aqueous $\mathrm{Ca}$ in the

572 DESMOS and North Su fluids at elevated temperatures, it is possible that anhydrite precipitation 573 may have influenced the measured $\Sigma \mathrm{SO}_{4}$ concentrations which, in turn, would introduce

574 systematic errors to the estimation of the endmember magmatic values. Measured $\mathrm{Ca}$

575 concentrations in some fluids, however, are above values expected for mixing of seawater and a magmatic fluid (Fig. 2), which by analogy to $\mathrm{Na}, \mathrm{K}$, and $\mathrm{Mg}$, would be expected to contain near

577 zero-Ca. Concentrations of $\mathrm{Ca}$ in 2006 that are above values expected for conservative mixing 578 suggest previously deposited anhydrite may be dissolving in subsurface environments, contributing both $\mathrm{Ca}$ and $\mathrm{SO}_{4}$ to solution. Reported concentrations of Ca in 1995 (Gamo et al., 580 1997) that are below values expected for conservative mixing (Fig. 2) suggest an earlier period 581 of anhydrite precipitation. Anhydrite is a common subsurface mineral at SuSu Knolls and would 582 likely dissolve or precipitate to maintain equilibrium with the fluid as temporal and spatial 583 variations in temperature and fluid composition change the saturation state of ascending fluids. 584 Although addition of $\mathrm{SO}_{4}$ by anhydrite dissolution would result in end-member $\Sigma \mathrm{SO}_{4}$ 585 concentrations that are systematically too high, the relatively minor enrichment of $\mathrm{Ca}$ above the 
dilution trend for seawater (Fig. 2) indicates that the effect on extrapolated $\Sigma \mathrm{SO}_{4}$ values is

587 relatively minor.

Other magmatic volatile species also show large enrichments in the acid-sulfate fluids. Estimated end-member $\Sigma \mathrm{CO}_{2}$ concentrations range from 142 to $341 \mathrm{mmol} / \mathrm{kg}$ (Fig. 4b, Table 2),

590 values that are well below $\mathrm{CO}_{2}$ solubility at seafloor pressures, consistent with the absence of

591 liquid $\mathrm{CO}_{2}$ associated with the white smoker vents. The extrapolated endmember $\mathrm{Cl}$

592 concentration in the NS1, NS2, and D1 fluids vary from 152 to $209 \mathrm{mmol} / \mathrm{kg}$. Extrapolation of

593 the measured $\mathrm{Cl}$ abundance in the D2 fluid to zero $\mathrm{Mg}$ results in an apparent negative end-

594 member concentration (Fig. 4c) that may reflect analytical uncertainty and large extrapolation

595 errors due to the near-seawater Mg concentration for this fluid, but it may also indicate non-

596 conservative behavior of $\mathrm{Mg}$ in the upflow zone. That the measured $\mathrm{Na}$ and $\mathrm{K}$ concentrations in

597 the D2 fluid are also slightly below values predicted for conservative mixing (Fig. 2) suggests

598 that a minor amount of $\mathrm{Mg}(<2 \mathrm{mmol} / \mathrm{kg})$ may have been added to the fluid before and/or after 599 mixing.

600 Based on the compositions of olivine-hosted melt inclusions from Pual Ridge that contain

601 F (Yang and Scott, 2002), and the substantial F enrichments in PACMANUS hydrothermal

602 fluids (Reeves et al. 2011), a contribution of F from a magmatic fluid is also to be expected at

603 DESMOS and North Su. Extrapolation of measured F concentrations to zero-Mg, however,

604 yields both negative and positive values (Fig. 4d). Apparent negative values are not possible and

605 indicate removal of $\mathrm{F}$ from solution during upflow. Laboratory experiments have demonstrated

606 rapid F-fixation during heating of seawater at 150 to $250^{\circ} \mathrm{C}$ that was best accounted for by

607 substitution of F for hydroxyl groups in hydrous phases (Seyfried and Ding, 1995). In contrast, at

608 temperatures $\geq 250^{\circ} \mathrm{C}$, F solubility was observed to increase due to enhanced stability of the

609 aqueous $\mathrm{HF}^{\circ}$ complex (Seyfried and Ding, 1995). The primary magmatic F contribution in acid-

610 sulfate fluids is likely obfuscated by both enrichment and depletion owing to fixation in or

611 mobilization from abundant hydroxyl-bearing minerals such as alunite and pyrophyllite in

612 advanced argillic assemblages over the broad range of temperatures that occur as a consequence

613 of subsurface mixing at DESMOS and SuSu Knolls. Nonetheless, the maximum end-member F

614 concentration calculated for the acid-sulfate fluids is $552 \mu \mathrm{mol} / \mathrm{kg}$, which is approximately two

615 orders of magnitude lower than the other volatile magmatic species, suggesting that it is a

616 relatively minor component of the magmatic fluid. Collectively, the composition of acid-sulfate 
617 fluids indicates an end-member magmatic fluid phase where $\mathrm{H}_{2} \mathrm{O}>\mathrm{SO}_{2}>\mathrm{CO}_{2} \approx \mathrm{Cl}>\mathrm{F}$ defines the

618 relative abundance of dominant constituents, and generally resembles the composition of

619 magmatic fluids inferred to have exsolved from highly fractionated felsic magmas at

620 PACMANUS (Yang and Scott, 2002; Reeves et al. 2011).

621 The composition of end-member magmatic fluids can also be used to assess the extent

622 that acidic volatiles influence the measured $\mathrm{pH}$ of acid-sulfate fluids at DESMOS and North Su.

623 The amounts of acidity added to the vent fluids can be calculated by assuming conservative

624 mixing of the magmatic end-member fluid and seawater assuming that a mole of $\mathrm{HCl}$ and a mole

625 of $\mathrm{H}_{2} \mathrm{SO}_{4}$ contribute one and two equivalents of acidity, respectively. Calculating the $\mathrm{pH}\left(25^{\circ} \mathrm{C}\right)$

626 of the mixed fluids requires accounting for the speciation of aqueous sulfate species because

$627 \mathrm{HSO}_{4}{ }^{-}$is a weak acid $\left(\mathrm{p} K_{a}=2.0\right.$ at $25^{\circ} \mathrm{C}$ and $\left.100 \mathrm{KPa}\right)$ and seawater and magmatic-derived

$628 \Sigma \mathrm{SO}_{4}$ exist as both $\mathrm{HSO}_{4}{ }^{-}$and $\mathrm{SO}_{4}{ }^{2-}$ at the $\mathrm{pH}$ of the mixed fluids. Using activity coefficients for

629 charged species calculated for a seawater salinity fluid, estimated $\mathrm{pH}\left(25^{\circ} \mathrm{C}\right)$ values show

630 excellent agreement with values measured for the fluids sampled as DESMOS and North $\mathrm{Su}$

631 (Fig. 6). The small positive departure of the estimated $\mathrm{pH}$ relative to the measured value for the

632 D2 fluid likely reflects the absence of a reliable estimate for the abundance of $\mathrm{HCl}$ in the

633 magmatic end-member that would contribute additional acidity. The similarity of measured and

634 estimated $\mathrm{pH}\left(25^{\circ} \mathrm{C}\right)$ provides additional evidence confirming magmatic volatiles as the

635 dominant source of acidity in acid-sulfate fluids at DESMOS and North Su. Moreover, the

636 conservative behavior of acidity during upflow and mixing with seawater indicates that $\mathrm{pH}$ is not

637 modified by extensive fluid-rock interactions in the subsurface, consistent with the lack of large

638 enrichments in the abundance of the major cations $\mathrm{Na}, \mathrm{K}$, and $\mathrm{Mg}$ and preservation of seawater

639 abundance ratios.

\subsubsection{Thermal Constraints}

642 Further confirmation that magmatic fluid-seawater mixing is generating acid-sulfate

643 fluids is provided by their measured temperatures. The observation that replicate fluid samples

644 from a given vent yield reproducible $\mathrm{Mg}$ concentrations indicates that subsurface mixing is

645 occurring prior to venting. This allows the Mg concentrations of the fluids exiting the seafloor to

646 be used together with the maximum measured vent temperatures to estimate the end-member

647 temperature of the magmatic fluid. For the purpose of these calculations, enthalpy values for 
648 pure water from the NIST Chemistry WebBook (Linstrom and Mallard, 2014) were employed 649 along with the assumption that enthalpy is conserved during mixing. Although the use of 650 enthalpy values for pure water introduces a small amount of error into these calculations, the 651 absence of an equation of state for variable composition and salinity fluids over the entire 652 temperature range of interest precludes a more rigorous approach. Heat capacity data for 653 seawater salinity fluids at a given temperature and pressure (Bischoff and Rosenbauer, 1985) are 654 lower than that of pure water resulting in a maximum error of approximately $20^{\circ} \mathrm{C}$ for the 655 calculated temperatures during mixing (Fig. 7). Examination of Figure 7 reveals estimated end656 member magmatic temperatures that vary from 600 to $1000^{\circ} \mathrm{C}$, a range that is consistent with 657 likely temperatures for silicic magmas existing in this region of the Manus Basin (Sinton et al., 658 2003). This range is comparable to that estimated for magmas associated with terrestrial 659 fumaroles in subduction-related settings, (e.g. Giggenbach, 1992; Hedenquist et al., 1994; 660 Hedenquist and Lowenstern, 1994). The ability of the above approach to predict magmatic 661 temperatures along with the strong correlation between measured temperature and $\mathrm{Mg}$ that 662 passes through $2{ }^{\circ} \mathrm{C}$, suggest that conductive heating of seawater is not occurring to a significant 663 extent prior to mixing of these fluids.

664 In contrast to black-smoker fluids that require conductive heating of seawater in the 665 vicinity of a crustal magma chamber or hot rock prior to convective transport to the seafloor (Alt, 666 1995), the primary mechanism for heat transport in areas of acid-sulfate fluid venting is by direct 667 advection of magmatic volatiles from crustal magma chambers. Because volatiles contain a small 668 fraction of the heat available within a magma body, the amount of heat that can be removed by 669 this mechanism is substantially less than during convective circulation of seawater-derived 670 hydrothermal fluids that can access the entire heat inventory within a magma chamber via 671 thermal conduction. This has important implications for the cooling of oceanic crust since 672 venting of acid-sulfate fluids is unlikely to play a significant role in the cooling of sub-seafloor 673 magma chambers or newly erupted lavas.

674 The chemical composition and heat content of acid-sulfate fluids at DESMOS and North

675 Su can be accounted for by mixing of hot magmatic volatiles and cold unmodified seawater 676 followed by chemical interaction with highly altered rocks within hydrothermal upflow zones.

677 There are significant differences between this model and that postulated for the formation of 678 black-smoker type fluids in back-arc and arc environments that have implications for chemical 
exchange and subsurface alteration processes. Perhaps most important, is that the formation of

680 acid-sulfate fluids at DESMOS involves the mixing of two endmember fluids, magmatic

681 volatiles and cold seawater, whereas formation of nearby black-smoker fluids (e.g. at

682 PACMANUS, or at the summit of North $\mathrm{Su}$ ) typically contain variable contributions from three

683 endmember fluids; an evolved seawater-derived hydrothermal fluid that has experienced

684 extensive interaction with unaltered rocks at low water/rock ratio, a magmatic volatile-rich fluid,

685 and unmodified cold seawater (de Ronde et al., 2011; Mottl et al., 2011; Reeves et al., 2011).

686 Black smoker fluids are characterized by higher $\mathrm{pH}\left(25^{\circ} \mathrm{C}\right)$ relative to acid-sulfate fluids and,

687 prior to mixing with cold-seawater, the near quantitative removal of aqueous $\mathrm{SO}_{4}$ (de Ronde et

688 al., 2011; Mottl et al., 2011; Reeves et al., 2011). For black-smoker fluids that contain a

689 significant magmatic component, the higher $\mathrm{pH}$ and absence of aqueous $\mathrm{SO}_{4}$ derived from

690 magmatic $\mathrm{SO}_{2}$ disproportionation (reactions 1 and 2) requires a mechanism to titrate acidity and

691 remove $\mathrm{SO}_{4}$ from solution following the addition of acidic magmatic volatiles. Exchange of $\mathrm{H}^{+}$

692 for cations such as $\mathrm{Na}^{+}, \mathrm{K}^{+}, \mathrm{Ca}^{2+}$, and $\mathrm{Fe}^{2+}$ during interaction with relatively fresh rock

693 represents a viable mechanism to titrate acidity and release rock-derived Ca necessary to remove

$694 \mathrm{SO}_{4}$ as anhydrite $\left(\mathrm{CaSO}_{4}\right)($ Seyfried, 1987). Continuous access to fresh rock by black smoker

695 fluids following the addition of magmatic volatiles likely reflects the progression of a cracking

696 front to adjacent the magma chamber as rocks solidify and contract in response to efficient heat

697 extraction by convecting hydrothermal fluids (Lister, 1974; 1983). Thus, the apparent paucity of

698 fresh rock encountered during the formation of acid-sulfate fluids may reflect the absence of

699 thermal convection that is responsible for the heat extraction necessary to induce thermal

700 cracking during the cooling of crustal rocks.

\subsubsection{Isotopic Constraints}

703 The origin of acidic and sulfate-rich fluids venting at DESMOS and North Su can be

704 further assessed by examining the abundance of stable hydrogen and oxygen isotopes in water,

705 carbon isotopes in dissolved $\mathrm{CO}_{2}$, and sulfur isotopes in $\Sigma \mathrm{SO}_{4}$. The measured hydrogen isotopic

706 composition of $\mathrm{H}_{2} \mathrm{O}$ in these fluids varies from -1 to $-8 \%$ and the oxygen isotopic composition

707 from 0.2 to $2.2 \%$; values consistent with the isotopic composition of fluids sampled at

708 DESMOS in 1995 by Gamo et al. (1997). Gena et al. (2006) calculated a similar isotopic

709 composition for the hydrothermal fluids that produced kaolinite-bearing alteration assemblages 
710 at DESMOS. The substantial D depletions that characterize the DESMOS and North Su fluids 711 are in marked contrast to the D enrichments observed in typical basalt-hosted black-smoker

712 fluids that result from hydration reactions during fluid-rock interaction at elevated temperatures 713 and pressures (Bowers and Taylor, 1985; Bowers, 1989; Shanks et al., 1995; Shanks, 2001).

714 Although negative $\delta \mathrm{D}$ values in the acid-sulfate fluids could be produced by fluid interaction 715 with nearby hemipelagic sediments at DESMOS and North Su (Shanks, 2001), such interaction 716 would likely be accompanied by the production of thermogenic $\mathrm{CH}_{4}$ from sedimentary organic 717 matter (Seewald et al., 1990; 1994). The low abundance of $\mathrm{CH}_{4}$ in these fluids (Table 1)

718 indicates that extensive interaction with sediments has not occurred. It is possible to generate 719 negative $\delta \mathrm{D}$ values for low salinity hydrothermal fluids during some open system scenarios of 720 subcritical phase separation (Berndt et al., 1996), but these involve unusually extreme distillation 721 of vapor phases, or phase separation of pre-existing brines. Given the other compositional 722 attributes of these fluids, the negative $\delta \mathrm{D}$ values for acid-sulfate and black-smoker fluids in the 723 Eastern Manus Basin can be attributed to the subsurface addition of magmatic volatiles and 724 subsequent mixing with seawater (Gamo et al., 1997; Gena et al., 2006; Reeves et al., 2011). 725 If a model involving the mixing of a Mg-free aqueous magmatic fluid and seawater as 726 described above is embraced for the origin of acid-sulfate fluids at DESMOS and North Su, the 727 isotopic composition of the magmatic end-member can be calculated by linearly extrapolating 728 the measured isotopic compositions to zero Mg. Although this can be done for all the sampled 729 fluids, large extrapolation errors result for vent fluids that contain near seawater $\mathrm{Mg}$ 730 concentrations due to the magnitude of analytical uncertainties associated with the hydrogen 731 isotopic measurements. Accordingly, magmatic end-members were not calculated for the D2 and 732 NS1 vents, which had compositions close to seawater. Extrapolation of the measured isotopic 733 compositions for the D1 and NS2 vents to zero Mg yields an end-member magmatic volatile 734 characterized by $\delta \mathrm{D}$ values of -31 and $-26 \%$ and $\delta^{18} \mathrm{O}$ values of 6.5 and $8.3 \%$, respectively. 735 Examination of Figure 8 reveals that these values are far more D-enriched than typical juvenile 736 mantle derived magmatic $\mathrm{H}_{2} \mathrm{O}$ (Taylor, 1979b; Ohmoto, 1986). While isotope fractionation 737 effects during degassing from silicic magma could substantially enrich the D content of exsolved 738 juvenile $\mathrm{H}_{2} \mathrm{O}$ (e.g. Holloway and Blank, 1994), the values calculated above are similar to 739 estimated compositions of waters degassed from arc magmas argued to have been 740 compositionally modified by 'devolved seawater' from the subducting slab (Giggenbach, 1992; 
741 Hedenquist and Lowenstern, 1994; Shaw et al., 2008). This agreement is noteworthy since the 742 isotopic compositions of magmatic fluid calculated here are extrapolated from near seawater 743 compositions, whereas the devolved seawater composition discussed by Giggenbach (1992) were 744 extrapolated from compositions heavily diluted by meteoric waters characterized by much lower $745 \delta \mathrm{D}$ values.

The acid-sulfate vents at DESMOS and North Su suggest the widespread occurrence of such isotopic compositions in subduction-related settings, and provide compelling evidence for a 748 contribution of slab-derived $\mathrm{H}_{2} \mathrm{O}$ to melts generated in the back-arc environment of the Eastern 749 Manus Basin. This is consistent with numerous geochemical proxies (e.g. higher Ba/ $\mathrm{Nb}$ and $750 \mathrm{Cl} / \mathrm{Nb}$ ratios in dredged lavas) that indicate substantial subduction-related inputs to magmas in 751 the Eastern Manus volcanic zone (Kamenetsky et al., 2001; Sinton et al., 2003; Sun et al., 2004; 752 Pearce and Stern, 2006; Park et al., 2010). In addition to hydrated basaltic crust, sediments 753 overlaying the Solomon Sea plate undergoing subduction beneath the New Britain arc are 754 characterized by indurated mudrocks (claystones and calcareous mudstones) and pelagic 755 limestones (Crook, 1987) that would contribute water compositionally similar to the estimates of 756 Giggenbach (1992). This conclusion differs from the model proposed previously for the 757 formation of DESMOS acid-sulfate fluids that involves addition of juvenile mantle-derived $\mathrm{H}_{2} \mathrm{O}$ 758 characterized by the $\delta \mathrm{D}$ values of -40 to $-80 \%$ (Gamo et al., 1997; Gena et al., 2006).

759 Additional evidence documenting a contribution of volatiles from the subducting slab 760 underlying the Eastern Manus Basin volcanic zone is provided by the carbon isotopic 761 compositions of $\Sigma \mathrm{CO}_{2}$ in DESMOS and North Su acid-sulfate fluids that vary from -2.8 to -4.6 $762 \%$ when corrected for the contribution of admixed seawater (Table 2). This range of values is 763 enriched in ${ }^{13} \mathrm{C}$ relative to $\Sigma \mathrm{CO}_{2}$ observed in basalt-hosted mid-ocean ridge hydrothermal fluids 764 with $\delta^{13} \mathrm{C}$ values that typically vary from -4 to $-9 \%$ (Kelley et al., 2004). The relatively high $765 \quad \delta^{13} \mathrm{C}_{\mathrm{CO} 2}$ values suggest a contribution of ${ }^{13} \mathrm{C}$-enriched carbon to magmatic fluids from slab766 derived carbonates (Alt and Teagle, 1999; Coltice et al., 2004). Although fluid interaction with 767 nearby hemipelagic sediments at DESMOS and North Su could result in the dissolution of ${ }^{13} \mathrm{C}$ 768 enriched marine carbonate and an increase in the $\delta^{13} \mathrm{C}_{\mathrm{CO} 2}$ values of acid-sulfate fluids, as 769 discussed above, low values of $\mathrm{CH}_{4}$ in DESMOS and North Su acid-sulfate fluids indicate that 770 interaction with sediments is not occurring to a significant extent. The range of $\delta^{13} \mathrm{C}_{\mathrm{CO} 2}$ values in 771 the acid-sulfate fluids at DESMOS and North $\mathrm{Su}$ are similar to the those for $\Sigma \mathrm{CO}_{2}$ in vent fluids 
772 from the nearby PACMANUS vent field (-2.3 to $-4.1 \%$ ), but are enriched relative to $\Sigma \mathrm{CO}_{2}$ from

773 the Vienna Woods vent field (-5.2 to $-5.7 \%$ ), approximately $170 \mathrm{~km}$ to the west (Reeves et al.,

774 2011). Elevated ${ }^{13} \mathrm{C}$ contents in the eastern most vent fields likely reflects an increased

775 contribution of slab-derived $\mathrm{CO}_{2}$ as the New Britain arc is approached (Fig. 1). Values of $\delta^{13} \mathrm{C}$

776 for magmatic $\mathrm{CO}_{2}$ venting at Rabaul Caldera locate at the New Britain Arc vary from -2 to $-5 \%$

777 (Perez et al., 1996), almost identical to the range observed here for DESMOS and North Su. A

778 similar trend has been observed in Lau Basin where the influence of the subducting slab on the

779 composition of ridge-crest vent fluids increases systematically from north to south as the back-

780 arc spreading center approaches the Tofua arc (Proskurowski et al., 2007; Mottl et al., 2011).

781 The observed $\mathrm{S}$ isotope fractionation between dissolved $\mathrm{SSO}_{4}$ and particulate elemental

$782 \mathrm{~S}^{(0)}$ collected in the IGT samplers is consistent with $\mathrm{SO}_{2}$ disproportionation via reaction (2) at

783 temperatures expected for this reaction (Figure 5). Measured $\delta^{34} \mathrm{~S}_{\mathrm{SO} 4}$ values undoubtedly contain

784 a contribution of seawater-derived $\Sigma \mathrm{SO}_{4}$ and must be corrected to estimate the $\delta^{34} \mathrm{~S}_{\mathrm{SO} 4}$ value of

785 the magmatic $\mathrm{SO}_{2}$-derived fraction of $\Sigma \mathrm{SO}_{4}$. Using only fluids that show minimal deviations in

786 measured Ca (D1, NS1 and NS2) and are therefore not substantially affected by anhydrite

787 dissolution or precipitation, the following isotope mass balance for $\delta^{34} \mathrm{~S}_{\mathrm{SO} 4}$ values of measured

$788 \quad \mathrm{SSO}_{4}$ can be assumed:

$$
\delta^{34} \mathrm{~S}_{\mathrm{SO} 4(\text { meas })}=\delta^{34} \mathrm{~S}_{\mathrm{SO} 4(\mathrm{sw})} * F_{\mathrm{SO} 4(\mathrm{sw})}+\delta^{34} \mathrm{~S}_{\mathrm{SO} 4(\mathrm{mag})} *\left(1-F_{\mathrm{SO} 4(\mathrm{sw})}\right)
$$

where $F_{\mathrm{SO} 4(\mathrm{sw})}$ is the fraction of the measured $\Sigma \mathrm{SO}_{4}$ concentration assumed to be derived from seawater $\Sigma \mathrm{SO}_{4}$ and $\delta^{34} \mathrm{~S}_{\mathrm{SO} 4(\text { meas) }}, \delta^{34} \mathrm{~S}_{\mathrm{SO} 4(\mathrm{sw})}$, and $\delta^{34} \mathrm{~S}_{\mathrm{SO} 4(\mathrm{mag})}$ refer to the sulfur isotopic

794 composition of measured, seawater-, and magmatic-derived $\Sigma \mathrm{SO}_{4}$, respectively. Given the likely 795 conservative behavior of admixed seawater $\mathrm{Mg}$ and $\Sigma \mathrm{SO}_{4}$ following disproportionation discussed previously, it is assumed that $F_{\mathrm{SO} 4(\mathrm{sw})}$ is directly proportional to the measured $\mathrm{Mg}$ concentration:

$$
F_{\mathrm{SO} 4(\mathrm{sw})}=\left([\mathrm{Mg}]_{\text {meas }} /[\mathrm{Mg}]_{\mathrm{sw}}\right) *\left(\left[\Sigma \mathrm{SO}_{4}\right]_{\mathrm{sw}} /\left[\Sigma \mathrm{SO}_{4}\right]_{\text {meas }}\right)
$$
where square brackets refer to the aqueous concentration of the species indicated. Values of $801 \delta^{34} \mathrm{~S}_{\mathrm{SO} 4(\mathrm{mag})}$ calculated from equation (3) range from +7.0 to $+14.1 \%$ at DESMOS and North Su 802 (Table 2). While disproportionation may be happening over a range of temperatures during fluid 
803 ascent and mixing, $\delta^{34} \mathrm{~S}$ values of particulate elemental $\mathrm{S}^{(0)}$ found in the fluid samplers (Table 1)

804 provide the closest possible estimate of the isotopic composition of $S^{(0)}$ likely produced in

805 association with magmatic $\mathrm{SO}_{2}$-derived $\Sigma \mathrm{SO}_{4}$ in the acid-sulfate fluids. The difference between

$806 \delta^{34} \mathrm{~S}$ values for $\mathrm{SO}_{2}$-derived $\Sigma \mathrm{SO}_{4}$ and particulate $\mathrm{S}^{(0)}$ at both DESMOS and North $\mathrm{Su}$

$807 \quad\left(\Delta^{34} \mathrm{~S}_{\mathrm{SO} 4 \leftrightarrow \mathrm{S}(0)}\right)$ varies from 12.2 to $17.7 \%$. Based on equilibrium fractionation factors determined

808 experimentally by Kusakabe et al. (2000) from 150 to $326^{\circ} \mathrm{C}$, and the isotopic composition of

$809 \mathrm{SO}_{2}$-derived $\Sigma \mathrm{SO}_{4}$ and particulate $\mathrm{S}^{(0)}$, equilibrium temperatures in excess of $400{ }^{\circ} \mathrm{C}$ are

810 estimated, considerably higher than measured seafloor vent temperatures.

\section{$812 \quad 5.2$ Comparison with previous studies}

813 Comparison of the fluid chemistry presented here for the DESMOS vent area with the

814 composition of DESMOS fluids in 1995 and 1998 (Gamo et al., 1997; Gena et al., 2006) reveals

815 both similarities and differences. In general, the compositions of the 1995 fluids are consistent

816 with the dilution trends that result from the dilution of seawater by a water-rich magmatic fluid

817 (Figs. 2 and 4). Fluids collected in 2006, however, contain lower fractions of admixed seawater,

818 allowing us to better resolve the composition of the magmatic end-members. The reason for this

819 difference is not clear, but could reflect differences in the sampling devices used for fluid

820 collection or temporal variability in subsurface hydrology. DESMOS fluids venting at the

821 seafloor in 2006 contain substantially greater Al concentrations than were observed in 1995. The

822 high levels of dissolved Al suggest that fluids of this type may be responsible for the formation

823 of Al-rich plumes observed in the water column $200 \mathrm{~m}$ above the seafloor in 1990 (Gamo et al.,

824 1993). Measured aqueous Al abundances and temperatures at DESMOS in 2006 suggest that

825 dilution factors of 2000 to 4000 would be required to account for the observed water-column

826 temperature anomaly of $0.03^{\circ} \mathrm{C}$ and 320 to 1000 to account for the maximum $1.5 \mu \mathrm{mol} / \mathrm{kg} \mathrm{Al}$

827 anomaly (Gamo et al., 1993). Moreover, Values of Al/Mn in the 2006 DESMOS vent fluids

828 vary from 8 to 37 , a range of values that shows significant overlap with the range of $\mathrm{Al} / \mathrm{Mn}$ in the

8291990 plume that vary from 10 to 18 (Gamo et al., 1993).

830 Maximum measured temperatures at the DESMOS area of venting have remained

831 relatively constant from 88 to $120{ }^{\circ} \mathrm{C}$ in 1995 (Gamo et al. 1997) to 70 to $117{ }^{\circ} \mathrm{C}$ in 2006 , but

832 temporal changes in dissolved $\mathrm{S}$ species are apparent that likely reflect variability in the extent of

833 magmatic $\mathrm{SO}_{2}$ degassing and subsequent disproportionation reactions. In particular, the 
834 measured $\Sigma \mathrm{H}_{2} \mathrm{~S}: \Sigma \mathrm{SO}_{4}$ ratio of the fluids has systematically decreased in fluids collected on three 835 different sampling occasions during this period. The highest $\mathrm{\Sigma H}_{2} \mathrm{~S}$ concentration of $8.1 \mathrm{mmol} / \mathrm{kg}$ 836 was measured in 1995 (Gamo et al., 1997), but decreased to $2.8 \mathrm{mmol} / \mathrm{kg}$ in 1998 (Gena et al., 837 2006), and to $<0.5 \mathrm{mmol} / \mathrm{kg}$ in 2006. Maximum measured $\Sigma \mathrm{SO}_{4}$ concentrations, in contrast, 838 increased from $32.8 \mathrm{mmol} / \mathrm{kg}$ in 1995 (Gamo et al. 1997) to $51.6 \mathrm{mmol} / \mathrm{kg}$ in 1998 (Gena et al. 8392006 ) to $125 \mathrm{mmol} / \mathrm{kg}$ in 2006. These trends cannot be explained by different seawater:magmatic 840 fluid mixing ratios, given the similarities in the estimated extent of dilution between 1995 and 8412006 based on Mg concentrations and measured temperatures. While it is not possible to assess 842 the fraction of residual $\mathrm{SO}_{2}$ that was present in the 1995 fluids collected by Gamo et al. (1997), 843 the measured $\Sigma \mathrm{H}_{2} \mathrm{~S}$ and $\Sigma \mathrm{SO}_{4}$ data combined suggest a magmatic $\mathrm{SO}_{2}$ contribution of 844 approximately $0.3 \mathrm{~mol} / \mathrm{kg}$. This is substantially less than the $1.2 \mathrm{~mol} / \mathrm{kg}$ calculated in 2006 , 845 assuming negligible residual $\mathrm{SO}_{2}$ in the 1995 fluids. The 2006 increase must reflect an increased 846 abundance in the magmatic end-member since seawater:magmatic fluid ratios appear to have 847 remained constant. An increase in the total $\mathrm{S}$ content (i.e. initial $\mathrm{SO}_{2}$ ) of the magmatic fluid 848 venting at DESMOS that is accompanied by a marked decrease in the abundance of $\Sigma \mathrm{H}_{2} \mathrm{~S}$ from 8491995 to 2006 is consistent with a shift from disproportionation proceeding via both reactions (1) 850 and (2) in 1995 and 1998, to disproportionation occurring exclusively via reaction (2) in 2006 851 (Figure 5). Increased acidity that would accompany increases in the contribution of magmatic $852 \mathrm{SO}_{2}$ to venting fluids may also account for the enhanced $\mathrm{Al}$ dissolution and lower $\mathrm{pH}$ of fluids in 853 2006. Temporal changes in $\mathrm{SO}_{2}$ fluxes on yearly to decadal timescales at DESMOS are similar to 854 the variations reported for subaerial volcanic systems (e.g. Caltabiano et al., 1994; Kusakabe et 855 al., 2000) and likely reflect changes in subsurface magmatic activity.

856 Further evidence pointing to an increase in the flux of magmatic $\mathrm{SO}_{2}$ instead of 857 temperature as the likely cause for changes in the DESMOS acid-sulfate fluids between 1995 and 8582006 includes the broad similarity in temperatures of $\mathrm{SO}_{2}$ disproportionation estimated from both 859 datasets. Based on the $\mathrm{S}$ isotope fractionation between dissolved $\Sigma \mathrm{H}_{2} \mathrm{~S}$ and $\Sigma \mathrm{SO}_{4}\left(\Delta^{34} \mathrm{~S}_{\mathrm{SO} 4 \leftrightarrow \mathrm{H} 2 \mathrm{~S}}\right)$ 860 at DESMOS in 1995, Gamo et al. (1997) argued that disproportionation was occurring via 861 reaction (1) at a temperature of $\sim 250^{\circ} \mathrm{C}$, much lower than temperature estimates based on the 8622006 compositions. However, the interpretation of Gamo et al. (1997) does not fully correct for 863 the contribution of seawater-derived $\Sigma \mathrm{SO}_{4}$ and therefore overestimates the magmatic $\delta^{34} \mathrm{~S}_{\mathrm{SO} 4}$ 864 value. The reported isotopic and chemical compositions for the $88^{\circ} \mathrm{C}$ fluid collected in 1995 
865 (samples 302-1 and 302-2 from Gamo et al., 1997), equations (3) and (4), and the temperature 866 dependency for equilibrium $\mathrm{SO}_{4}-\mathrm{H}_{2} \mathrm{~S}$ isotopic fractionation determined by Ohmoto and Lasaga

867 (1982) yield $\Delta^{34} \mathrm{~S}_{\mathrm{SO} 4 \leftrightarrow \mathrm{H} 2 \mathrm{~S}}$ values of 16.3 and $18.0 \%$ o that suggest much higher temperatures from 868335 to $368^{\circ} \mathrm{C}$ in 1995 . Isotopic data for elemental $\mathrm{S}^{(0)}$ collected in 1995 immediately adjacent to 869 the 302-1 and 302-2 samples during the same dive (Gena et al., 2006) allows estimation of 870 temperature based on $\mathrm{SO}_{4}-\mathrm{S}^{(0)}$ fractionation. Using the magmatic $\delta^{34} \mathrm{~S}_{\mathrm{SO} 4}$ values calculated for 8711995 , estimated $\Delta^{34} \mathrm{~S}_{\mathrm{SO} 4 \leftrightarrow \mathrm{S}(0)}$ values range from 17.3 to $20.0 \%$ and yield $\Sigma \mathrm{SO}_{4}-\mathrm{S}^{(0)}$ equilibrium 872 temperatures $>350^{\circ} \mathrm{C}$. Collectively, these observations suggest the temperature range in which 873 disproportionation likely occurred in 1995 is indistinguishable from that of the 2006 fluids, and 874 suggest that temperature is not the dominant factor responsible for the shift in disproportionation 875 mechanisms.

876 Direct addition of magmatic volatiles to highly acidic, sulfate-rich vent fluids has also 877 been reported for hydrothermal activity during active eruption of the NW Rota-1 submarine 878 volcano in the southern Mariana Arc (Butterfield et al., 2011). These fluids are characterized by $879 \mathrm{pH}\left(25^{\circ} \mathrm{C}\right)$ values as low as $1.0, \Sigma \mathrm{SO}_{4}$ concentrations as high as $165 \mathrm{mmol} / \mathrm{kg}$, and aqueous $\mathrm{Al}$ 880 concentrations as high as $2.6 \mathrm{mmol} / \mathrm{kg}$ (Butterfield et al., 2011). They are likely responsible for 881 the formation of Al- and S-rich hydrothermal plumes in the overlying water column at NW Rota8821 (Resing et al., 2007). Similarly high Al concentrations were detected in plume waters collected 883 above the DESMOS caldera (Gamo et al., 1993). Although shallow water depth at NW Rota-1 $884(520 \mathrm{~m})$ relative to the DESMOS and North $\mathrm{Su}$ results in the formation of $\mathrm{CO}_{2}$-rich gas bubbles 885 and partitioning of magmatic volatiles between liquid water and a gas phase, the fundamental 886 process of magmatic degassing, seawater mixing, and fluid-rock interaction with a highly altered 887 mineral assemblage may be very similar to that occurring in the Manus Basin. Indeed, 888 extrapolation of magmatically derived total dissolved sulfur present in the aqueous phase from 889 the Brimstone vent at NW Rota-1 (Butterfield et al. 2011) to zero Mg yields a magmatic end890 member of $\sim 1.1 \mathrm{~mol} / \mathrm{kg}$ that is similar to the magmatic end-member of $1.2 \mathrm{~mol} / \mathrm{kg}$ for the D1 891 vent. The similarity of the NW Rota-1 fluids with those observed at DESMOS and North Su 892 where active eruptions were not observed, suggests that production of acid-sulfate fluids may not 893 be a unique feature of volcanic eruptions, but instead reflects the presence of significant magma 894 accumulations at shallow levels within the ocean crust. 


\section{IMPLICATIONS AND SUMMARY}

The chemistry of acid-sulfate fluids at SuSu Knolls and DESMOS and other acid-sulfate

900 systems points to an origin involving the mixing of magmatic volatiles with seawater and

901 chemical interaction with highly altered crustal rocks. The high acidity of these fluids results in

902 intense alteration of the oceanic crust and the aqueous mobilization of metals such as Al that are

903 relatively immobile under more alkaline conditions. Substantial compositional differences

904 between acid-sulfate and black smoker fluids suggest that the influence of acid-sulfate venting

905 on global hydrothermal fluxes may differ signficantly. The large enrichments of Al and total S in

906 acid-sulfate fluids from near-arc environments have been used in conjunction with estimates for

907 the arc-associated hydrothermal heat output to estimate the global flux of these species

908 (Butterfield et al., 2011). Results presented here, however, suggest that the volume of acid-

909 sulfate fluids venting in back-arc and arc-environments is ultimately constrained by the volume

910 of magmatic volatiles, not the magmatic heat budget, since the lack of convective hydrothermal

911 circulation limits their ability to mine heat from the oceanic crust. The majority of crustal cooling

912 in back-arc and near-arc environments likely occurs by convective circulation of seawater-

913 derived black-smoker fluids that are also abundantly present in these environments, but contain

914 substantially lower concentrations of Al and S species (Fouquet et al., 1993; Auzende et al.,

915 1996; Gamo et al., 1996a,b; Ishibashi et al., 1996; Douville et al., 1999a,b ; Fourre et al., 2006;

916 Takai et al., 2008; Butterfield et al., 2011; Mottl et al., 2011; Reeves et al., 2011). Accordingly,

917 global flux calculations that use hydrothermal heat flux to constrain the mass of acid-sulfate

918 fluids venting in back-arc and arc environments may substantially overestimate the contribution

919 of $\mathrm{Al}$ and $\mathrm{S}$ to the oceans.

920 In addition to chemical fluxes to the ocean, the volume of acid-sulfate fluids venting in

921 back-arc and arc environments has important implications for the spatial extent of crustal

922 alteration. Rock composition may be extensively changed during interaction with acid-sulfate

923 fluids due to the efficiency with which cations are leached under highly acidic conditions and is

924 evident in the occurrence of argillic and advanced argillic alteration assemblages where

925 magmatic degassing is prevalent (e.g. Gena et al., 2001). The spatial extent of such alteration,

926 however, is limited by the volume of acid-sulfate fluids and subsurface hydrogeology that 
927 regulates fluid flow above a degassing magma chamber. Relative to seawater-derived black-

928 smoker fluids that can access a significant portion of magmatic heat available in a subseafloor 929 magma chamber during convective circulation, the volume of acid-sulfate fluids will likely be

930 substantially smaller. Moreover, the low abundance of mobile trace elements such as $\mathrm{Cs}, \mathrm{Rb}$, and

$931 \mathrm{Li}$ in acid-sulfate fluids indicates that they have not reacted with large quantities of fresh rock,

932 requiring fluid-rock interaction under fluid-dominated conditions. In contrast, black-smoker

933 fluids from oceanic spreading centers are highly enriched in $\mathrm{Cs}, \mathrm{Rb}$, and $\mathrm{Li}$ indicating interaction

934 with fresh rock under conditions of low water/rock ratio facilitated by a migrating cracking front

935 (Lister, 1974). Greater volumes of fluid interacting with the crust under conditions of

936 lower/water rock ratio requires that the volumetric extent of crustal alteration by black-smoker

937 fluids is substantially greater than that occurring in response to venting of acid-sulfate fluids.

938 The role of magmatic volatiles during ore formation has been discussed extensively in the

939 literature ( $c f$. Hedenquist and Lowenstern, 1994; Yang and Scott, 1996). Some suggest that

940 magmatic volatiles are enriched in ore-forming metals derived directly from the magma while

941 others suggest that the extreme acidity of these fluids facilitates leaching of ore-forming metals

942 from surrounding rocks. Owing to the trace abundance of ore-forming metals in crustal rocks in

943 back-arc and arc environments, the leaching model requires interaction of acid-sulfate fluids with

944 substantial quantities of crustal rocks. The volume of acid-sulfate fluids may be limited by the

945 availability of magmatic volatiles which, in turn, may limit the volume of crustal rock that

946 undergoes direct leaching by such fluids. However, the addition of acidic magmatic volatiles to

947 convective black smoker fluids, as has been suggested for other back-arc convective

948 hydrothermal systems (de Ronde et al., 2005; 2011; Mottl et al., 2011; Reeves et al., 2011) may

949 allow magmatically-derived acidity to access larger volumes of rock and their associated ore-

950 forming metals. The role of magmatically derived vent fluids presented in this study during ore-

951 formation is further complicated by the absence of significant $\Sigma \mathrm{H}_{2} \mathrm{~S}$ that precludes precipitation

952 of large quantities of metal sulfides at or below the seafloor, and the absence of a mechanism to

953 titrate the extreme acidity that is necessary to induce precipitation below the seafloor. Indeed, a

954 characteristic trait of the acidic metal-rich fluids venting in places like DESMOS and North Su is

955 the lack of sulfide deposition associated with white smokers. Additional information regarding

956 the abundance of ore-forming metals in acid-sulfate fluids and the extent to which magmatic

957 degassing influences the mobilization of metals in seawater-derived black-smoker fluids is 
958 required to better constrain the role of magmatic volatiles during ore-formation processes. On a 959 broader scale, more widespread geochemical characterization of acid-sulfate fluids emanating 960 from volcanic edifices in back-arc and intraoceanic arc settings will allow for a greater

961 understanding of how these fluids influence geochemical fluxes, ocean chemistry and recycling 962 processes associated with subduction.

963 
We thank the Jason group and the crew of the RV Melville for their expertise, assistance, and dedication that contributed to a very successful field program. The authors thank Dr.

968 Matthew Leybourne and two anonymous reviewers for their insightful comments that improved

969 the paper. This study received financial support from NSF Grant OCE-0327448, the WHOI Deep 970 Ocean Exploration Institute Graduate Fellowship to E.P. Reeves, the Ocean Drilling Program

971 Schlanger Fellowship to P.R. Craddock and a fellowship from the Hanse-Wissenschaftskolleg to 972 J.S. Seewald. 
Alt, J. C. (1995) Subseafloor processes in mid-ocean ridge hydrothermal systems. In: Seafloor Hydrothermal Systems: Physical, Chemical, Biological, and Geological Interactions, (Ed: S. E. Humphris, R. A. Zierenberg, L. S. Mullineaux, and R. E. Thomson), AGU Monograph, 91, American Geophysical Union. pp. 85-114.

Alt J. C. and Teagle D.A.H. (1999) The uptake of carbon during alteration of ocean crust. Geochim. Cosmochim. Acta 63, 1527-1535.

Alt J. C. and Bach W. (2003) Alteration of oceanic crust: subsurface water-rock interactions. In: Dahlem Workshop Report: Energy and Mass Transfer in Marine Hydrothermal Systems, Halbach, P. E., Tunnicliffe, V., and Hein, J. R. (Ed.). Dahlem University Press.

Auzende J.M., Urabe T., Ruellan E., Chabroux D., Charlou J.L., Gena K., Gamo T., Henry K., Matsubayashi O., Matsumoto T. et al. (1996) "Shinkai 6500" Dives in the Manus Basin: New STARMER Japanese-French Program. JAMSTEC Journal of Deep Sea Research 12, 323-334.

Auzende J.M., Hashimoto J., Fialamedioni A., and Ohta S. (1997) In situ geological and biological study of two hydrothermal zones in the Manus Basin (Papua New Guinea). Comptes Rendus De L Academie Des Sciences Serie Ii Fascicule A-Sciences De La Terre Et Des Planetes 325(8), 585-591.

Auzende J.M., Ishibashi J., Beaudoin Y., Charlou J.L., Delteil J., Donval J.P., Fouquet Y., Gouillou J.P., Ildefonse B., Kimura H. et al. (2000) The eastern and western tips of Manus Basin (Papua, New Guinea) explored by submersible; MANAUTE cruise. Comptes Rendus De L Academie Des Sciences Serie Ii Fascicule A-Sciences De La Terre Et Des Planetes 331(2), 119-126.

Berndt, M. E., Seal, R. R., Shanks, W. C., and Seyfried, W. E. (1996) Hydrogen isotope systematics of phase separation in submarine hydrothermal systems: Experimental calibration and theoretical models. Geochim. Cosmochim. Acta 60(9), 1595-1604.

Bezos A., Escrig S., Langmuir C.H., Michael P.J., and Asimow P.D. (2009) Origins of chemical diversity of back-arc basin basalts: A segment scale study of the Eastern Lau Spreading Center. Journal of Geophysical Research 114, B06212, http://dx.doi.org/10.1029/2008JB005924. 
Binns R.A. and Scott S.D. (1993) Actively forming polymetallic sulfide deposits associated with felsic volcanic-rocks in the Eastern Manus Back-Arc Basin, Papua New Guinea. Economic Geology 88(8), 2226-2236.

Binns R.A., Scott S.D., Gemmell J.B., Crook K., and Party S.S. (1997) The SuSu Knolls Hydrothermal Field, Eastern Manus Basin, Papua New Guinea. EOS Trans. AGU, 78(722), Fall Meet. Suppl. Abstract V22E-02.

Binns R.A., Barriga F.J.A.S., and Miller D.J. (2007) Leg 193 Synthesis: Anatomy of an active felsic-hosted hydrothermal system, Eastern Manus Basin, Papua New Guinea. In: Proceedings of the Ocean Drilling Program, Scientific Results, (Ed: F. J. A. S. Barriga, R. A. Binns, D. J. Miller, and P. M. Herzig), 193, pp. 1-71.

Bischoff J.L. and Rosenbauer R.J. (1985) An emprical equation of state for hydrothermal seawater (3.2 percent NaCl), Amer. J. Sci. 285, 725-763.

Both R., Crook K., Taylor B., Brogan S., Chappell B., Frankel E., Liu L., Sinton J., and Tiffin D. (1986) Hydrothermal chimneys and associated fauna in the Manus back-arc basin, Papua New Guinea. EOS Trans. AGU 67, 489-491.

Bowers T.S. and Taylor H.P. (1985) An integrated chemical and stable-isotope model of the origin of midocean ridge hot spring systems. Journal of Geophysical Research 90(B14), 12583-12606.

Bowers T.S. (1989) Stable isotope signatures of water-rock interaction in mid-ocean ridge hydrothermal systems: sulfur, oxygen and hydrogen. Journal of Geophysical Research 94(B5), 5775-5786.

Butterfield D.A., Nakamura K., Takano B., Lilley M.D., Lupton J.E., Resing J.A., and Roe K.K. (2011) High $\mathrm{SO}_{2}$ flux, sulfur accumulation, and gas fractionation at an erupting submarine volcano. Geology 39, 803-806.

Butterfield, D., Seyfried, W. E., and Lilley, M. (2003) Composition and evolution of hydrothermal fluids. In: Dahlem Workshop Report: Energy and Mass Transfer in Marine Hydrothermal Systems, (Ed: P. E. Halbach, V. Tunnicliffe, and J. R. Hein), 89, Dahlem University Press. pp. 123-161.

Caltabiano T., Romano R., and Budetta G. (1994) $\mathrm{SO}_{2}$ flux measurements at Mount Etna (Sicily). Journal of Geophysical Research-Atmospheres 99, 12809-12819. 
1034 Carroll M. R. and Rutherford M. J. (1988) Sulfur speciation in hydrous experimental glasses of varying oxidation state: Results from measured wavelength shifts of sulfur x-rays. American Mineralogist 73, 845-849.

Carroll M. R. and Webster J. D. (1994) Solubilities of sulfur, noble gases, nitrogen, chlorine, and fluorine in magmas. In: Volatiles in magmas, Reviews in Mineralogy, 1, pp231-279. Carroll, M. R. and Holloway, J. R. (Ed.). Mineralogical Society of America.

Charlou J.L., Donval J.P., Douville E., Jean-Baptiste P., Knoery J., Fouquet Y., Dapoigny A., and Stievenard M. (2000) Compared geochemical signature and evolution of Menez Gwen (37j50VN) and Lucky Strike (37j17VN) hydrothermal fluids, south of the Azores Triple Junction on the Mid-Atlantic Ridge. Chem. Geol. 171, 49- 75.

Charlou, J. L., Donval, J. P., Fouquet, Y., Jean-Baptiste, P., and Holm, N. (2002) Geochemistry of high $\mathrm{H} 2$ and $\mathrm{CH} 4$ vent fluids issuing from ultramafic rocks at the Rainbow hydrothermal field (36 14'N, MAR). Chemical Geology 191(4), 345-359.

Coltice N., Simon L., and Lecuyer C. (2004) Carbon isotope cycle and mantle structure. Geophysical Research Letters 31(5).

Craddock P. R., Bach W., Seewald J. S., Rouxel O. J., Reeves E., and Tivey M. K. (2010) Rare earth element abundances in hydrothermal fluids from the Manus Basin, Papua New Guinea: Indicators of sub-seafloor hydrothermal processes in back-arc basins. Geochim. Cosmochim. Acta 74, 5494-5513.

Crook K. (1987) Petrology and mineral chemistry of sedimentary rocks from the Western Solomon Sea. Geo-Marine Letters 6, 203-209.

de Ronde C.E.J. (1995) Fluid chemistry and isotopic characteristics of seafloor hydrothermal systems and associated VMS deposits: potential for magmatic contribution, in: Thompson, J.F.H. (Ed.), Magmas, fluids, and ore deposits. Mineralogical Association of Canada, Victoria, British Columbia, pp. 479-509.

de Ronde C.E.J. (2011) Submarine hydrothermal activity and gold-rich mineralization at Brothers Volcano, Kermadec Arc, New Zealand. Mineralium Deposita 46, 541-584. de Ronde, C. E. J., Hannington, M. D., Stoffers, P., Wright, I. C., Ditchburn, R. G., Reyes, A. G., Baker, E. T., Massoth, G. J., Lupton, J. E., Walker, S. L. et al. (2005) Evolution of a submarine magmatic-hydrothermal system: Brothers volcano, southern Kermadec arc, New Zealand. Economic Geology 100(6), 1097-1133. 
1065 de Ronde C.E.J., Massoth G.J., Barker E.T., and Lupton J.E. (2003) Submarine hydrothermal 1066 venting related to volcanic arcs. In: Simmons SF, Graham I (eds) Society of Economic 1067 Geologists, Inc., Special Publication, pp 91-110

1068 Douville E., Bienvenu P., Charlou J.L., Donval J.P., Fouquet Y., Appriou P., and Gamo T. 1069 (1999a) Yttrium and rare earth elements in fluids from various deep-sea hydrothermal 1070 systems. Geochim. Cosmochim. Acta 63(5), 627-643.

Douville E., Charlou J.L., Donval J.P., Hureau D., and Appriou P. (1999b) As and Sb behaviour in fluids from various deep-sea hydrothermal systems. Comptes Rendus de L'Academie des Sciences Serie Ii Fascicule A-Sciences de La Terre et des Planetes 328(2), 97-104.

Embley, R. W., Chadwick, W. W., Baker, E. T., Butterfield, D. A., Resing, J. A., De Ronde, C.

Drummond S. E. (1981) Boiling and mixing of hydrothermal fluids: Chemical effects on mineral precipitation, Ph.D. Dissertation, Penn. State University.

Eickmann, B., Bach, W., Rosner, M., and Peckmann, J. (2009) Geochemical constraints on the modes of carbonate precipitation in peridotites from the Logatchev Hydrothermal Vent Field and Gakkel Ridge. Chemical Geology 268(1-2), 97-106. E. J., Tunnicliffe, V., Lupton, J. E., Juniper, S. K., Rubin, K. H. et al. (2006) Long-term eruptive activity at a submarine arc volcano. Nature 441(7092), 494-497.

Escrig S., Bezos A., Goldstein S.L., Langmuir C.H., and Michael P.J. (2009) Mantle source variations beneath the Eastern Lau Spreading Center and the nature of subduction components in the Lau Basin-Tonga arc system. Geochemistry Geophysics Geosystems 10, Q04014, http://dx.doi.org/10.1029/2008GC002281.

Fouquet Y., Vonstackelberg U., Charlou J.L., Erzinger J., Herzig P.M., Muhe R., and Wiedicke M. (1993) Metallogenesis in back-arc environments - The Lau Basin example. Economic Geology 88(8), 2154-2181.

Fourre E., Jean-Baptiste P., Charlou J. L., Donval J. P., and Ishibashi J. I. (2006) Helium isotopic composition of hydrothermal fluids from the Manus back-arc Basin, Papua New Guinea. Geochemical Journal 40, 245-252.

Gamo T., Sakai H., Ishibashi J., Nakayama E., Isshiki K., Matsuura H., Shitashima K., Takeuchi K., and Ohta S. (1993) Hydrothermal plumes in the Eastern Manus Basin, Bismarck Sea $\mathrm{CH}_{4}, \mathrm{Mn}, \mathrm{Al}$ and $\mathrm{pH}$ anomalies. Deep-Sea Research Part I-Oceanographic Research Papers 40(11-12), 2335-2349. 
1096

1097

1098

1099

1100

1101

1102

1103

1104

1105

1106

1107

1108

1109

1110

1111

1112

1113

1114

1115

1116

1117

1118

1119

1120

1121

1122

1123

1124

1125

Gamo, T., Okamura, K., Charlou, J. L., Urabe, T., Auzende, J. M., Cruise, S. S. P. O. T. M., Ishibashi, J., Shitashima, K., and Kodama, Y. (1996a) Chemical exploration of hydrothermal activity in the Manus Basin, Papua New Guinea (ManusFlux Cruise). JAMSTEC Journal of Deep Sea Research 12, 335-345.

Gamo, T., Okamura, K., Kodama, T., Charlou, J. L., Urabe, T., Auzende, J. M., Ishibashi, J., and Party, A. T. S. S. (1996b) Chemical characteristics of hydrothermal fluids from the Manus back-arc basin, Papua New Guinea, I. Major Chemical Components. EOS Trans. $A G U$ 77(W116), WPGM Suppl. Abstract T32A-5.

Gamo, T., Okamura, K., Charlou, J. L., Urabe, T., Auzende, J. M., Ishibashi, J., Shitashima, K., and Chiba, H. (1997) Acidic and sulfate-rich hydrothermal fluids from the Manus backarc basin, Papua New Guinea. Geology 25(2), 139-142.

Gamo, T., Ishibashi, J., Tsunogai, U., Okamura, K., and Chiba, H. (2006) Unique geochemistry of submarine hydrothermal fluids from arc-back-arc settings of the Western Pacific. In: Back-Arc Spreading Systems: Geological, Biological, Chemical, and Physical Interactions, (Ed: D. M. Christie, C. R. Fisher, S.-M. Lee, and S. Givens), AGU Monograph, 166, American Geophysical Union. pp. 147-161.

Gena K., Mizuta T., Ishiyama D., and Urabe T. (2001) Acid-sulphate type alteration and mineralization in the DESMOS caldera, Manus back-arc basin, Papua New Guinea. Resource Geology 51, 31-44.

Gena K. R., Chiba H., Mizuta T., and Matsubaya O. (2006) Hydrogen, oxygen and sulfur isotope studies of seafloor hydrothermal system at the Desmos caldera, Manus back-arc basin, Papua New Guinea: An analogue of terrestrial acid hot crater-lake. Resource Geology 56, 183-190.

German C. and Von Damm K.L. (2003) Hydrothermal Processes. In: The Treatise on Geochemistry, (Ed: K. K. Turekian and H. D. Holland), 6.07, Elsevier. pp. 181-222.

Giggenbach W. F. (1992) Isotopic shifts in waters from geothermal and volcanic systems along convergent plate boundaries and their origin. Earth Planet. Sci. Lett. 113, 495-510.

Giggenbach W. F. (1997) The Origin and Evolution of Fluids in Magmatic-Hydrothermal Systems. In: Geochemistry of Hydrothermal Ore Deposits, pp737-796. Barnes, H. L. (Ed.). Wiley. 
Gruen G., Weis P., Driesner T., Heinrich C.A., and de Ronde C.E.J. (2014) Hydrodynamic modeling of magmatic-hydrothermal activity atsubmarine arc volcanoes, with implications for ore formation.Hedenquist J. W., Aoki M., and Shinohara H. (1994) Flux Of Volatiles And Ore-Forming Metals From The Magmatic-Hydrothermal System Of Satsuma Iwojima Volcano. Geology 22, 585-588.

Hedenquist J. W. and Lowenstern J. B. (1994) The role of magmas in the formation of hydrothermal ore deposits. Nature 370, 519-527.

Heinrich C.A. (2005) The physical and chemical evolution of low-salinity magmatic fluids at the porphyry to epithermal transition: a thermodynamic study. Mineralium Deposita 39, 864889.

Helgeson H.C., Delany J.M., Nesbitt H.W., Bird D.K. (1978) Summary and critique of the thermodynamic properties of rock-forming minerals. Amer. J. Sci. 278A, 1-229.

Helgeson H.C., Kirkham D.H., and Flowers G.C. ( 1981 ) Theoretical prediction of the thermodynamic behavior of aqueous electrolytes at high pressures and temperatures. IV. Calculation of activity coefficients, osmotic coefficients, and apparent molal and standard and relative partial molal properties to $5 \mathrm{~kb}$ and $600^{\circ}$ C. Amer. J. Sci. 281, 1241-1516.

Holland H. D. (1965) Some applications of thermochemical data to problems in ore deposits II. Mineral assemblages and the composition of ore-forming fluids. Econ. Geol. 60, 11011166.

Holland H.D. and Malinin S.D. (1979) The solubility and occurrence of non-ore minerals. In Geochemistry qfHydrothermal Ore Deposits (ed, H.L. Barnes), pp. 461-508. Wiley.

Holloway J. R. and Blank J. G. (1994) Application of experimental results to C-O-H species in natural melts. Volatiles in Magmas 30, 187-230.

Hrischeva E., Scott S.D., and Weston R. (2007) Metalliferous sediments associated with presently forming volcanogenic massive sulfides: The SuSu knolls hydrothermal field, eastern manus basin, Papua New Guinea. Economic Geology 102(1), 55-73.

Huss A., Jr. , Lim P. K., and Eckert C. A. (1982) Oxidation of aqueous sulfur dioxide. 1. Homogeneous manganese(II) and iron(II) catalysis at low $\mathrm{pH}$. The Journal of Physical Chemistry 86, 4224-4228.

Ishibashi J., Wakita K., Okamura K., Gamo T., Shitashima K., Charlou J.L., Donval J.P., JeanBaptiste P., and Party A.T.S.S. (1996) Chemical characteristics of hydrothermal fluids 
from the Manus back-arc basin, Papua New Guinea, II. Gas Components. EOS Trans. $A G U$ 77(W116), WPGM Suppl. Abstract T32A-6.

Iwasaki I. and Ozawa T. (1960) Genesis of sulfate in acid hot spring. Bulletin of the Chemical Society of Japan 33, 1018-1019.

Johnson, J.W., Oelkers, E.H., Helgeson, H.C. (1992) SUPCRT92: a software package for calculating the standard molal thermodynamic properties of minerals, gases, aqueous species, and reactions from 1 to 5000 bar and 0 to $1000^{\circ}$ C. Comput. Geosci. 18, 899-947.

Kamenetsky V. S., Binns R. A., Gemmell J. B., Crawford A. J., Mernagh T. P., Maas R., and Steele D. (2001) Parental basaltic melts and fluids in eastern Manus backarc Basin: implications for hydrothermal mineralisation. Earth Planet. Sci. Lett. 184, 685-702.

Kelley D.S., Lilley M.D., and Früh-Green G.L. (2004) Volatiles in submarine environments: food for life. In: The Subseafloor Biosphere at Mid-Ocean Ridges, (Ed: W.S.D. Wilcock, E.F. DeLong, D.S. Kelley, J.A. Baross, and S.C. Cary), AGU Monograph, 144, American Geophysical Union. pp. 167-189.

Kendall, C. and Coplen, T. B. (1985) Multisample conversion of water to hydrogen by zinc for stable isotope determination. Analytical Chemistry 57(7), 1437-1440.

Kusakabe M., Komoda Y., Takano B., and Abiko T. (2000) Sulfur isotopic effects in the disproportionation reaction of sulfur dioxide in hydrothermal fluids: implications for the $\delta 34 \mathrm{~S}$ variations of dissolved bisulfate and elemental sulfur from active crater lakes. Journal of Volcanology and Geothermal Research 97, 287-307.

Lackschewitz K.S., Devey C.W., Stoffers P., Botz R., Eisenhauer A., Kummetz M., Schmidt M., and Singer A. (2004) Mineralogical, geochemical and isotopic characteristics of hydrothermal alteration processes in the active, submarine, felsic-hosted PACMANUS field, Manus Basin, Papua New Guinea. Geochim. Cosmochim. Acta 68(21), 4405-4427.

Leybourne M. I., Schwarz-Schampera U., de Ronde C. E. J., Baker E. T., Faure K., Walker S. L., Butterfield D. A., Resing J. A., Lupton J. E., Hannington M. D., Gibson H. L., Massoth G. J., Embley R. W., Chadwick W. W., Clark, M. R. Timm, C., Graham,I. J., and Wright I. C. (2012) Submarine Magmatic-Hydrothermal Systems at the Monowai Volcanic Center, Kermadec Arc. Econ. Geol. 107, 1669-1694.

Lilley, M. D., Butterfield, D. A., Lupton, J. E., and Olson, E. J. (2003) Magmatic events can produce rapid changes in hydrothermal vent chemistry. Nature 422(6934), 878-881. 
Linstrom P.J., and Mallard W.G. Eds., NIST Chemistry WebBook, NIST Standard Reference Database Number 69, National Institute of Standards and Technology, Gaithersburg MD, 20899, http://webbook.nist.gov, (retrieved September 29, 2014).Lisitsyn A.P., Crook K., Bogdanov Y.A., Zonenshain L.P., Murav'yev K.G., Tufar W., Gurvich Y.G., Gordeyev V.V., and Ivanov G.V. (1993) A hydrothermal field in the rift zone of the Manus Basin, Bismarck Sea. International Geology Review 35(2), 105-126.

Lister C.R.B. (1974) On the penetration of water into hot rock. Geophys. J. R. Astron. Soc. 39, 465-509.

Lister C.R.B. (1983) On the intermittency and crystallization mechanisms of sub-seafloor magma chambers. Geophysical Journal of the Royal Astronomical Society 73(2), 351365.

Martinez, F. and Taylor, B. (1996) Backarc spreading, rifting, and microplate rotation, between transform faults in the Manus basin. Marine Geophysical Researches 18(2-4), 203-224.

Martinez F., Taylor B., Baker E.T., Resing J.A., and Walker S.L. (2006) Opposing trends in crustal thickness and spreading rate along the back-arc Eastern Lau Spreading Center: Implications for controls on ridge morphology, faulting, and hydrothermal activity. Earth and Planet. Sci. Lett. 245:655-672, http://dx.doi.org/10.1016/j.eps1.2006.03.049.

Moss, R. and Scott, S. D. (2001) Geochemistry and mineralogy of gold-rich hydrothermal precipitates from the eastern Manus Basin, Papua New Guinea. Canadian Mineralogist 39, 957-978.

Mottl M. J., Seewald J. S., Wheat C. G., Tivey M. K., Michael P. J., Proskurowski G., McCollom T. M., Reeves E., Sharkey J., You C. F., Chan L. H., and Pichler T. (2011) Chemistry of hot springs along the Eastern Lau Spreading Center. Geochim. Cosmochim. Acta 75, 1013-1038.

Ohmoto H. (1986) Stable isotope geochemistry of ore deposits. In: Stable Isotopes in High Temperature Geological Processes, (Ed: J. W. Valley, H. P. Taylor, and J. R. O'Neil), Reviews in Mineralogy, 16, Mineralogical Society of America. pp. 491-559.

Ohmoto H. and Lasaga A. C. (1982) Kinetics of reactions between aqueous sulfates and sulfides in hydrothermal systems. Geochim. Cosmochim. Acta 46, 1727-1745. 
1217 Park, S. H., Lee, S.-M., Kamenov, G. D., Kwon, S.-T., and Lee, K.-Y. (2010) Tracing the origin 1218 of subduction components beneath the South East rift in the Manus Basin, Papua New 1219 Guinea. Chemical Geology 269, 339-349.

1220 Paulick H. and Bach W. (2006) Phyllosilicate mineralogy of the submarine, dacite-hosted, Pacmanus hydrothermal system - integration of SWIR, XRD, and geochemical data (Papua New Guinea, ODP Leg 193). Econ. Geol. 101, 633-650.

Pearce J. A. and Stern R. J. (2006) Origin of back-arc basin magmas: trace element and isotope perspectives In: Back-Arc Spreading Systems: Geological, Biological, Chemical, and Physical Interactions, AGU Monograph, pp63-86. Christie, D. M., Fisher, C. R., Lee, S.M., and Givens, S. (Ed.). American Geophysical Union.

Pérez N.M., Wakita H., Lolok D. Patia H. Talai B., and McKee C.O. (1996) Anomalous soil gas $\mathrm{CO}_{2}$ concentrations and relation to seismic activity at Rabaul caldera, Papua New Guinea. Geogaceta 20(4), 1000-1003.

1230 Pester N.J., Reeves E.P., Rough M.E., Ding K., Seewald J.S., Seyfried W.E. Jr. (2012) Subseafloor phase equilibria in high-temperature hydrothermal fluids of the Lucky Strike Seamount (Mid-Atlantic Ridge, 37¹7’N). Geochim. Cosmochim. Acta 90, 303-322.

1233 Proskurowski G., Seewald J.S., Reeves E., Mccollo TM., Lupton J., Sylva S.P., and Tivey M.K. (2007) Volatile chemistry at Lau Basin hydrothermal sites: Basin-wide trends of slab

Rees C. E., Jenkins W. J., and Monster J. (1978) Sulfur isotopic composition of ocean water sulfate. Geochim. Cosmochim. Acta 42, 377-381. carbonate influence and suggestions of abiotic methane oxidation at the Mariner vent site. EOS Trans. AGU 88(52), Fall Meet. Suppl. V34B-04.

Resing J. A., Lebon G., Baker E. T., Lupton J. E., Embley R. W., Massoth G. J., Chadwick W. W., and De Ronde C. E. J. (2007) Venting of acid-sulfate fluids in a high-sulfidation setting at NW Rota-1 submarine volcano on the Mariana Arc. Econ. Geol. 102, 10471061. 
1247 Scaillet B. and Pichavant M. (2003) Experimental constraints on volatile abundances in arc magmas and their implications for degassing processes. Geological Society, London, Special Publications 213, 23-52.

Seewald, J., Cruse, A., and Saccocia, P. (2003) Aqueous volatiles in hydrothermal fluids from the Main Endeavour Field, northern Juan de Fuca Ridge: temporal variability following earthquake activity. Earth Planet. Sci. Lett. 216(4), 575-590.

Seewald J.S., Doherty K.W., Hammar T.R., and Liberatore S.P. (2002) A new gas-tight isobaric sampler for hydrothermal fluids. Deep-Sea Research Part I-Oceanographic Research Papers 49(1), 189-196.

Seewald J.S. and Seyfried W.E. Jr. (1990). The effect of temperature on heavy and base metal mobility in subseafloor hydrothermal systems: constraints from basalt alteration experiments and field studies. Earth Planet. Sci. Lett., 101, 388-403.

Seewald J.S., Seyfried W.E. Jr., and Shanks W.C. III (1994). Variations in the chemical and stable isotope composition of carbon and sulfur species during organic-rich sediment alteration: An experimental and theoretical study of hydrothermal activity at Guaymas Basin, Gulf of California. Geochim. Cosmochim. Acta 58, 5065-5082.

Seewald J.S., Seyfried W.E. Jr., and Thornton E.C. (1990). Organic-rich sediment alteration: An experimental and theoretical study at elevated temperatures and pressures. Applied Geochemistry, 5, 193-209.Seyfried, W. E. (1987) Experimental and theoretical constraints on hydrothermal alteration processes at mid-ocean ridges. Annual Review of Earth and Planetary Sciences 15, 317-335.

Seyfried W. E. (1987) Experimental and theoretical constraints on hydrothermal alteration processes at mid-ocean ridges. Annual Review of Earth and Planetary Sciences 15, 317335.

Seyfried W. E. and Ding K. (1995) The hydrothermal chemistry of fluoride in seawater. Geochimic. Cosmochim. Acta 59(6), 1063-1071.

Shanks W.C. III, Böhlke J.K., and Seal R.R. (1995) Stable isotopes in mid-ocean ridge hydrothermal systems: interactions between fluids, minerals, and organisms. In: Seafloor Hydrothermal Systems: Physical, Chemical, Biological, and Geological Interactions, (Ed: S. E. Humphris, R. A. Zierenberg, L. S. Mullineaux, and R. E. Thomson), AGU Monograph, 91, American Geophysical Union. pp. 194-221. 
Shanks W. C. III, (2001) Stable Isotopes in Seafloor Hydrothermal Systems: Vent fluids, hydrothermal deposits, hydrothermal alteration, and microbial processes. Reviews in Mineralogy and Geochemistry 43, 469-525.

Shaw A. M., Hauri E. H., Fischer T. P., Hilton D. R., and Kelley K. A. (2008) Hydrogen isotopes in Mariana arc melt inclusions: Implications for subduction dehydration and the deepEarth water cycle. Earth Planet. Sci. Lett. 275, 138-145.

Shock E.L. and Helgeson H.C., (1988) Calculation of the thermodynamic and transport properties of aqueous species at high pressures and temperatures: correlation algorithms for ionic species and equation of state predictions to $5 \mathrm{~kb}$ and $1000{ }^{\circ} \mathrm{C}$. Geochim. Cosmochim. Acta 52, 2009-2036.

Shock E. L., Helgeson H. C., and Sverjensky D. A. (1989) Calculation of the thermodynamic and transport properties of aqueous species at high pressures and temperatures: Standard partial molal properties of inorganic neutral species. Geochim. Cosmochim. Acta 53, 2157-2183.

Shock E. L., Sassani D. C., Willis M., and Sverjensky D. A. (1997) Inorganic species in geologic fluids: Correlations among standard molal thermodynamic properties of aqueous ions and hydroxide complexes. Geochim. Cosmochim. Acta 61, 907-950.

Sinton J. M., Ford L. L., Chappell B., and McCulloch M. T. (2003) Magma genesis and mantle heterogeneity in the Manus back-arc basin, Papua New Guinea. Journal Of Petrology 44, 159-195.

Sun, W. D., Arculus, R. J., Kamenetsky, V. S., and Binns, R. A. (2004) Release of gold-bearing fluids in convergent margin magmas prompted by magnetite crystallization. Nature 431(7011), 975-978.

Sverjensky D.A., Shock E.L., and Helgeson H.C. (1997) Prediction of the thermodynamic properties of aqueous metal complexes to $1000^{\circ} \mathrm{C}$ and $5 \mathrm{~kb}$. Geochim. Cosmochim. Acta. 61, 1359-1412.

Tagirov B. and Schott J. (2001) Aluminum speciation in crustal fluids revisited. Geochim. Cosmochim. Acta 65, 3965-3992.

Takai, K., Nunoura, T., Ishibashi, J. I., Lupton, J., Suzuki, R., Hamasaki, H., Ueno, Y., Kawagucci, S., Gamo, T., Suzuki, Y. et al. (2008) Variability in the microbial communities and hydrothermal fluid chemistry at the newly discovered Mariner 
hydrothermal field, southern Lau Basin. Journal of Geophysical ResearchBiogeosciences 113(G02031), doi:10.1029/2007JG000636.

Taylor, B. (1979a) Bismarck Sea: evolution of a back-arc basin. Geology 7(171-174).

1312 Taylor, B., Crook, K., and Sinton, J. (1994) Extensional transform zones and oblique spreading centers. Journal Of Geophysical Research-Solid Earth 99(B10), 19707-19718.

1314 Taylor, H. P. (1979b) Oxygen and hydrogen isotope relationships in hydrothermal mineral

1315 deposits. In: Geochemistry of Hydrothermal Ore Deposits, (Ed: H. L. Barnes), Wiley. pp. 1316 236-277.

1317 Taylor H. P. (1986) Magmatic volatiles: isotopic variation of C, H, and S. In: Stable isotopes in 1318 high temperature geological processes, Reviews in Mineralogy, 16, pp185-225. Valley, 1319 J. W., Taylor, H. P., and O'Neil, J. R. (Ed.). Mineralogical Society of America.

1320 Tivey, M., Bach, W., Seewald, J., Tivey, M. K., Vanko, D. A., and the Shipboard Science, J. I. A. A. T. T. (2006) Cruise Report for R/V Melville cruise MGLNO6MV - Hydrothermal

1325 Trefry J. H., Butterfield D. B., Metz S., Massoth G. J., Trocine R. P., and Feely R. A. (1994) systems in the Eastern Manus Basin: Fluid Chemistry and Magnetic Structure as Guides to Subseafloor Processes. Woods Hole Oceanographic Institution (available upon request

1328 Tregoning, P. (2002) Plate kinematics in the western Pacific derived from geodetic observations. Journal Of Geophysical Research-Solid Earth 107(B1). Trace metals in hydrothermal solutions from cleft segment on the southern Juan De Fuca

Von Damm, K. L. (1995) Controls on the chemistry and temporal variability of seafloor hydrothermal systems. In: Seafloor Hydrothermal Systems: Physical, Chemical, Biological, and Geological Interactions, (Ed: S. E. Humphris, R. A. Zierenberg, L. S. Mullineaux, and R. E. Thomson), AGU Monograph, 91, American Geophysical Union. pp. 222-247. 
1338 Von Damm, K. L., Edmond, J. M., Grant, B., and Measures, C. I. (1985) Chemistry of submarine hydrothermal solutions at $21^{\circ} \mathrm{N}$, East Pacific Rise. Geochim. Cosmochim. Acta 49(11), 2197-2220.

1341 Wolery T.J. (1992) EQ3NR, A Computer Program for Aqueous Speciation-Solubility

1342 Calculations: Theoretical Manual, Users's Guide, and related Documentation. Lawrence $1343 \quad$ Livermore National Lab.

1344 Yang K. H. and Scott S. D. (1996) Possible contribution of a metal-rich magmatic fluid to a sea1345 floor hydrothermal system. Nature 383, 420-423.

1346 Yang K. H. and Scott S. D. (2002) Magmatic degassing of volatiles and ore metals into a 1347 hydrothermal system on the modern sea floor of the eastern Manus back-arc basin, 1348 western Pacific. Econ. Geol. 97, 1079-1100.

1349 Yang K. H. and Scott S. D. (2006) Magmatic fluids as a source of metals in seafloor 1350 hydrothermal systems. In: Back-Arc Spreading Systems: Geological, Biological, 1351 Chemical, and Physical Interactions, AGU Monograph, pp163-184. Christie, D. M., 1352 Fisher, C. R., Lee, S.-M., and Givens, S. (Ed.). American Geophysical Union. 
1356 Figure 1. Maps showing the location of a) the Manus Basin relative to the New Britain and New 1357 Ireland arcs, b) fluids sampled from the DESMOS caldera, and c) fluids sampled from North Su 1358 volcano (adapted from Tivey et al., 2006). EMZV in a) indicates the location of the Eastern 1359 Manus Volcanic Zone.

Figure 2. Concentrations of selected aqueous species versus aqueous $\mathrm{Mg}$ in acid-sulfate vent 1362 fluids collected from the DESMOS and North Su vent areas in 2006. Concentrations measured at 1363 DESMOS in 1995 by Gamo et al. (1997) are shown for comparison. Lines drawn from seawater 1364 to the origin show the effect of dilution by pure water.

Figure 3. Activity diagrams showing the stability of K-alunite and pyrrophillite in equilibrium with an aqueous phase for acid-sulfate vent fluids from the DESMOS and North Su vent areas at the indicated temperatures and $25 \mathrm{MPa}$. In situ activities of $\mathrm{H}^{+}, \mathrm{K}^{+}, \mathrm{Ca}^{2+}, \mathrm{SO}_{4}{ }^{2-}$, and $\mathrm{SiO}_{2(a q)}$ necessary for the construction of these diagrams were calculated using the computer program EQ3NR (Wolery, 1992) and the measured concentrations of aqueous species and temperatures at each vent. The error bars represent $0.5 \log$ units.

1373 Figure 4. Concentrations of selected aqueous species versus aqueous $\mathrm{Mg}$ in acid-sulfate vent 1374 fluids collected from the DESMOS and North Su vent areas in 2006.

1376 Figure 5. Activity-activity diagrams in the system $\mathrm{SO}_{2}-\mathrm{H}_{2} \mathrm{O}$ at $400^{\circ} \mathrm{C}(\mathbf{A})$ and $300^{\circ} \mathrm{C}$ (B) for a 1377 total $\mathrm{S}$ concentration $(\Sigma \mathrm{S})$ of $1.2 \mathrm{~mol} / \mathrm{kg} \mathrm{H}_{2} \mathrm{O}$ as a function of $\mathrm{pH}$ and dissolved $\mathrm{H}_{2}$ activity $\left(a_{\mathrm{H} 2}\right)$. 1378 Similar diagrams at $400^{\circ} \mathrm{C}(\mathbf{C})$ and $300^{\circ} \mathrm{C}$ (D) are shown for a $\Sigma \mathrm{S}$ concentration $0.3 \mathrm{~mol} / \mathrm{kg} \mathrm{H}_{2} \mathrm{O}$. 1379 All diagrams are constructed for a pressure of $40 \mathrm{MPa}$. Activity coefficients of unity have been 1380 assumed for all species included in these diagrams. The star represents the triple point where $1381 \mathrm{SO}_{2(\mathrm{aq})}, \mathrm{HSO}_{4}{ }^{-}$and either elemental $\mathrm{S}^{(0)}$ or $\mathrm{H}_{2} \mathrm{~S}_{(\mathrm{aq})}$ are in equilibrium. These diagrams were 1382 generated using thermodynamic data from Helgeson et al. (1978) and Shock et al. $(1989,1997)$. 1383 
1384 Figure 6. Calculated $\mathrm{pH}\left(25^{\circ} \mathrm{C}\right)$ versus measured $\mathrm{pH}\left(25^{\circ} \mathrm{C}\right)$ for acid-sulfate fluids from the 1385 DESMOS and North Su vent fields. The positive deviation of the D2 vent (open symbol) likely 1386 reflects the absence of data for the concentration of $\mathrm{HCl}$ in the end-member magmatic fluid that 1387 represents a source of acidity in these fluids.

1389 Figure 7. Measured temperatures versus aqueous $\mathrm{Mg}$ for acid-sulfate vent fluids collected from 1390 the DESMOS and North Su vent areas in 2006. The solid lines show predicted temperatures 1391 during mixing of Mg-free high temperature magmatic fluids (temperatures indicated) with a Mg1392 bearing $(53 \mathrm{mmol} / \mathrm{kg}) 2^{\circ} \mathrm{C}$ fluid. See text for details relevant to the construction of this figure. 1393

1394 Figure 8. End-member $\delta \mathrm{D}_{\mathrm{H} 2 \mathrm{O}}$ and $\delta^{18} \mathrm{O}_{\mathrm{H} 2 \mathrm{O}}$ values for vent fluids from the Manus Basin. Values 1395 for the Vienna Woods and PACMANUS vent fields are from Reeves et al. (2011). The shaded 1396 regions show the range of values for mantle-derived water (Taylor, 1979b; Ohmoto, 1986) and 1397 subduction related volcanic vapors (Giggenbach, 1992; Hedenquist and Lowenstern, 1994). The 1398 solid line represents a linear regression of the data from the PACMANUS and Vienna Woods 1399 hydrothermal fields. 
Table 1. Measured concentrations* and isotopic composition of aqueous species and sulfur particles in vent fluids from the DESMOS and SuSu Knolls Vent Fields.

\begin{tabular}{|c|c|c|c|c|c|c|c|c|c|c|c|c|c|c|c|c|c|c|}
\hline Sample & Vent & $\begin{array}{c}\mathrm{T}_{\max } \\
{ }^{\circ} \mathrm{C} \\
\end{array}$ & $\begin{array}{c}\mathrm{pH} \\
25^{\circ} \mathrm{C}\end{array}$ & $\begin{array}{l}\mathrm{Mg} \\
\mathrm{mm}\end{array}$ & $\begin{array}{l}\mathrm{Na} \\
\mathrm{mm}\end{array}$ & $\begin{array}{c}\mathrm{K} \\
\mathrm{mm}\end{array}$ & $\mathrm{Na} / \mathrm{K}$ & $\mathrm{K} / \mathrm{Mg}$ & $\mathrm{Na} / \mathrm{Mg}$ & $\begin{array}{r}\mathrm{Li} \\
\mu \mathrm{m} \\
\end{array}$ & $\begin{array}{l}\mathrm{Rb} \\
\mu \mathrm{m}\end{array}$ & $\begin{array}{l}\mathrm{Cs} \\
\mathrm{nm}\end{array}$ & $\begin{array}{l}\mathrm{Ca} \\
\mathrm{mm}\end{array}$ & $\begin{array}{l}\mathrm{Ba} \\
\mu \mathrm{m}\end{array}$ & $\begin{array}{l}\mathrm{Sr} \\
\mu \mathrm{m}\end{array}$ & $\begin{array}{c}{ }^{87} \mathrm{Sr} /{ }^{86} \mathrm{Sr} \\
\text { molal }\end{array}$ & $\begin{array}{r}\mathrm{Fe} \\
\mathrm{mm}\end{array}$ & $\begin{array}{l}\mathrm{Mn} \\
\mu \mathrm{m}\end{array}$ \\
\hline \multicolumn{19}{|l|}{ DESMOS } \\
\hline J2-220-IGT1 & D1 & 113 & 0.95 & 44.9 & 391 & 8.3 & 47 & 0.18 & 8.7 & 24 & 2.8 & 11 & 9.4 & nd & 71 & 0.70880 & 12.4 & 40 \\
\hline J2-220-IGT2 & D1 & 117 & 0.95 & 45.1 & 392 & 8.4 & 47 & 0.19 & 8.7 & 25 & 3.3 & 9 & 9.4 & nd & 72 & nd & 11.9 & 37 \\
\hline J2-220-M4 & D1 & nd & 1.27 & 50.0 & 438 & 9.2 & 48 & 0.18 & 8.8 & 29 & 0.8 & 8 & 9.8 & nd & 86 & nd & 5.62 & 28 \\
\hline J2-220-IGT4 & $\mathrm{D} 2$ & 70 & 1.41 & 49.3 & 422 & 8.7 & 48 & 0.18 & 8.6 & 31 & 3.1 & 8 & 11.9 & 4 & 78 & 0.70886 & 5.56 & 46 \\
\hline J2-220-IGT3 & D2 & 69 & 1.40 & 49.2 & 421 & 8.8 & 48 & 0.18 & 8.6 & 21 & 0.3 & 8 & 11.7 & 4 & 79 & nd & 5.46 & 46 \\
\hline $\mathrm{J} 2-220-\mathrm{M} 2$ & D2 & nd & 1.41 & 49.4 & 419 & 8.8 & 48 & 0.18 & 8.5 & 25 & 1.0 & 11 & 11.9 & nd & 80 & nd & 5.53 & 43 \\
\hline \multicolumn{19}{|l|}{ North Su } \\
\hline J2-221-IGT8 & NS1 & 47 & 1.87 & 50.4 & 453 & 10.0 & 45 & 0.20 & 9.0 & 30 & 0.7 & 33 & 9.7 & 11 & 85 & 0.70895 & 1.32 & 21 \\
\hline J2-221-IGT7 & NS1 & 48 & 1.79 & 49.6 & 447 & 9.8 & 46 & 0.20 & 9.0 & 35 & 1.9 & 40 & 9.6 & 12 & 86 & nd & 1.63 & 26 \\
\hline J2-221-M4 & NS1 & nd & 1.85 & 49.8 & 450 & 9.8 & 46 & 0.20 & 9.0 & 34 & 1.2 & 38 & 9.6 & nd & 87 & nd & 1.42 & 22 \\
\hline J2-221-IGT6 & NS2 & 206 & 0.87 & 39.2 & 340 & 7.8 & 44 & 0.20 & 8.7 & 27 & 1.0 & 64 & 8.9 & nd & 58 & 0.70870 & 3.10 & 81 \\
\hline J2-221-IGT5 & NS2 & 215 & 0.87 & 41.1 & 359 & 8.0 & 45 & 0.20 & 8.7 & 34 & 2.7 & 56 & 9.1 & nd & 64 & nd & 2.57 & 67 \\
\hline J2-221-M2 & NS2 & nd & 0.91 & 41.1 & 359 & 8.0 & 45 & 0.19 & 8.7 & 34 & 1.5 & 56 & 9.0 & nd & 63 & nd & 2.47 & 68 \\
\hline Bottom Seawater & & 3 & 7.9 & 52.4 & 471 & 9.9 & 48 & 0.19 & 9.0 & 28 & $1.3^{\mathrm{a}}$ & $2.3^{\mathrm{a}}$ & 10.5 & 0.14 & 91 & 0.70916 & 0.0 & 0.0 \\
\hline
\end{tabular}

$* \mathrm{mM}=\mathrm{mmol} / \mathrm{L}$ fluid, $\mathrm{mm}=\mathrm{mmol} / \mathrm{kg}$ fluid, $\mu \mathrm{m}=\mu \mathrm{mol} / \mathrm{kg}$ fluid, $\mu \mathrm{M}=\mu \mathrm{mol} / \mathrm{L}$ fluid, $\mathrm{nm}=\mathrm{nmol} / \mathrm{kg}$ fluid, $\mathrm{nd}=$ not determined.

${ }^{\dagger}$ measured $\Sigma \mathrm{SO}_{4}$ concentration in fluid aliquot that was not sparged with $\mathrm{N}_{2}$ prior to storage (see text).

* calculated as the difference between measured $\Sigma \mathrm{SO}_{4}$ concentrations in sparged and unsparged fluid samples (see text).

\# sulfur isopic composition of elemental sulfur particles filtered from fluid. Data from McDermott et al. (submitted)

${ }^{\mathrm{a}}$ Spencer et al. (1970), ${ }^{\mathrm{b}}$ Rees et al. (1978), ${ }^{\mathrm{c}}$ Sarmineto \& Gruber (2006), ${ }^{\mathrm{d}}$ Craig (1970), ${ }^{\mathrm{e}}$ Craig \& Gordon (1965), ${ }^{\mathrm{f}}$ Redfield \& Friedman (1965) 
Table 1 (continued)

\begin{tabular}{|c|c|c|c|c|c|c|c|c|c|c|c|c|c|c|c|c|c|}
\hline $\begin{array}{l}\mathrm{Al} \\
\mathrm{mm}\end{array}$ & $\begin{array}{l}\mathrm{Cl} \\
\mathrm{mm}\end{array}$ & $\begin{array}{l}\mathrm{Br} \\
\mu \mathrm{m}\end{array}$ & $\begin{array}{c}\mathrm{F} \\
\mu \mathrm{m}\end{array}$ & $\begin{array}{c}\Sigma \mathrm{SO}_{4} \\
\mathrm{~mm}\end{array}$ & $\begin{array}{c}\delta^{34} \mathrm{~S}_{\mathrm{SO} 4} \\
\% 0\end{array}$ & $\begin{array}{c}\Sigma \mathrm{SO}_{4 \mathrm{~ns}}^{\dagger} \\
\mathrm{mm}\end{array}$ & $\begin{array}{l}\mathrm{SO}_{2}{ }^{*} \\
\mathrm{~mm}\end{array}$ & $\begin{array}{c}\delta^{34} \mathrm{~S}_{\text {part }} \# \\
\% 0\end{array}$ & $\begin{array}{l}\mathrm{SiO}_{2} \\
\mathrm{mM}\end{array}$ & $\begin{array}{c}\mathrm{B} \\
\mu \mathrm{M}\end{array}$ & $\begin{array}{l}\mathrm{H}_{2} \\
\mu \mathrm{M}\end{array}$ & $\begin{array}{c}\Sigma \mathrm{H}_{2} \mathrm{~S} \\
\mathrm{mM}\end{array}$ & $\begin{array}{c}\mathrm{CH}_{4} \\
\mu \mathrm{M}\end{array}$ & $\begin{array}{c}\Sigma \mathrm{CO}_{2} \\
\mathrm{~mm}\end{array}$ & $\begin{array}{c}\delta^{13} \mathrm{C}_{\mathrm{CO} 2} \\
\%\end{array}$ & $\begin{array}{c}\delta^{18} \mathrm{O}_{\mathrm{H} 2 \mathrm{O}} \\
\% \%\end{array}$ & $\begin{array}{c}\delta \mathrm{D}_{\mathrm{H} 2 \mathrm{O}} \\
\% 0\end{array}$ \\
\hline 0.48 & 492 & 610 & 137 & 125 & nd & 147 & 22 & nd & 8.32 & 185 & 3.3 & 0.005 & 0.13 & 23 & nd & 0.7 & -4 \\
\hline 0.47 & 495 & 620 & 128 & 123 & 9.8 & 139 & 16 & -5.2 & 7.90 & 176 & 4.8 & 0.004 & 0.09 & 21 & -3.0 & 0.9 & -5 \\
\hline 0.21 & 523 & 713 & 85 & & nd & 80.0 & & -6.2 & 3.46 & 157 & nd & nd & nd & nd & nd & nd & \\
\hline 1.6 & 503 & 706 & 8 & 55.3 & 17.2 & 62.6 & 7 & nd & 5.66 & 194 & 2.6 & 0.35 & 0.02 & 11 & -3.6 & 0.6 & -3 \\
\hline 1.6 & 502 & 721 & 5 & 54.4 & 17.4 & 59.5 & 5 & nd & 5.65 & 185 & 1.7 & 0.41 & 0.02 & 11 & nd & 0.8 & -3 \\
\hline 1.6 & 501 & 719 & 4 & & nd & 61.7 & & nd & 5.66 & 185 & nd & nd & nd & nd & nd & nd & \\
\hline 0.18 & 527 & 787 & 46 & 35.3 & nd & 41.0 & 6 & nd & 3.04 & 176 & 11 & 0.50 & 0.39 & 16 & nd & 0.2 & -4 \\
\hline 0.21 & 520 & 774 & 55 & 37.4 & nd & 39.9 & 3 & nd & 3.66 & 185 & 12 & 0.63 & 0.40 & 20 & -2.4 & 0.7 & -1 \\
\hline 0.21 & 524 & 781 & 47 & & nd & 40.2 & & nd & 3.30 & 194 & nd & nd & nd & nd & nd & nd & \\
\hline 1.1 & 443 & 510 & 128 & 132 & 15.2 & 149 & 17 & -3.6 & 9.94 & 490 & 18 & $<0.002$ & 0.64 & 82 & nd & 1.5 & -5 \\
\hline 0.93 & 456 & 559 & 103 & 120 & 15.3 & 130 & 10 & -1.5 & 8.56 & 425 & 22 & $<0.002$ & 0.54 & 74 & -2.8 & 2.2 & -8 \\
\hline 0.94 & 457 & 550 & 90 & & nd & 132 & & -1.4 & 8.90 & 444 & nd & nd & nd & nd & nd & nd & \\
\hline 0.0 & 540 & 808 & 64 & 28.2 & $20.99^{\mathrm{b}}$ & - & - & - & $0.13^{\mathrm{c}}$ & 426 & 0.0 & 0.0 & 0.0 & 2.3 & $0.3^{\mathrm{d}}$ & $-0.17^{\mathrm{e}}$ & $-0.14^{\mathrm{g}}$ \\
\hline
\end{tabular}

$* \mathrm{mM}=\mathrm{mmol} / \mathrm{L}$ fluid, $\mathrm{mm}=\mathrm{mmol} / \mathrm{kg}$ fluid, $\mu \mathrm{m}=\mu \mathrm{mol} / \mathrm{kg}$ fluid, $\mu \mathrm{M}=\mu \mathrm{mol} / \mathrm{L}$ fluid, $\mathrm{nm}=\mathrm{nmol} / \mathrm{kg}$ fluid, $\mathrm{nd}=$ not determined.

${ }^{\dagger}$ measured $\Sigma \mathrm{SO}_{4}$ concentration in fluid aliquot that was not sparged with $\mathrm{N}_{2}$ prior to storage (see text).

${ }^{\ddagger}$ calculated as the difference between measured $\mathrm{\Sigma SO}_{4}$ concentrations in sparged and unsparged fluid samples (see text).

\# sulfur isopic composition of elemental sulfur particles filtered from fluid. Data from McDermott et al. (submitted)

${ }^{\mathrm{a}}$ Spencer et al. (1970), ${ }^{\mathrm{b}}$ Rees et al. (1978), ${ }^{\mathrm{c}}$ Sarmineto \& Gruber (2006), ${ }^{\mathrm{d}}$ Craig (1970), ${ }^{\mathrm{e}}$ Craig \& Gordon (1965), ${ }^{\mathrm{f}}$ Redfield \& Friedman (1965) 
Table 2. Calculated concentrations* and isotopic composition of selected species in end-member magamatic volaltile phases at the DESMOS and SuSu Knolls vent fields.

\begin{tabular}{|c|c|c|c|c|c|c|c|c|c|c|}
\hline $\begin{array}{c}\text { Field } \\
\text { Vent } \\
\end{array}$ & $\begin{array}{r}\mathrm{Cl} \\
\mathrm{mm}\end{array}$ & $\begin{array}{c}\mathrm{F} \\
\mu \mathrm{m}\end{array}$ & $\begin{array}{l}\mathrm{SO}_{4} \\
\mathrm{~mm}\end{array}$ & $\begin{array}{c}\delta^{34} \mathrm{~S}_{\mathrm{SO} 4(\mathrm{mag})}{ }^{\dagger} \\
\% 0 \\
\end{array}$ & $\begin{array}{l}\mathrm{SO}_{2} \\
\mathrm{~mm}\end{array}$ & $\begin{array}{c}\mathrm{SO}_{2 i n i t}{ }^{*} \\
\mathrm{~mm}\end{array}$ & $\begin{array}{l}\mathrm{CO}_{2} \\
\mathrm{~mm}\end{array}$ & $\begin{array}{c}\delta^{13} \mathrm{C}_{\mathrm{CO} 2} \\
\% 0\end{array}$ & $\begin{array}{c}\delta^{18} \mathrm{O}_{\mathrm{H} 2 \mathrm{O}} \\
\% 0\end{array}$ & $\begin{array}{c}\delta \mathrm{D}_{\mathrm{H} 2 \mathrm{O}} \\
\% \text { o }\end{array}$ \\
\hline \multicolumn{11}{|c|}{$\overline{D E S M O S}$} \\
\hline D1 & 209 & 552 & 710 & 7.0 & 131 & 1196 & 142 & -3.4 & 6.5 & -31 \\
\hline D2 & nd & nd & 474 & 13.9 & 103 & 814 & 142 & -4.6 & nd & nd \\
\hline \multicolumn{11}{|c|}{ North Su } \\
\hline NS1 & 176 & nd & 205 & 14.1 & 80 & 388 & 341 & -2.8 & nd & nd \\
\hline NS2 & 152 & 258 & 446 & nd & 58 & 727 & 326 & -2.9 & 8.3 & -26 \\
\hline
\end{tabular}

$* \mathrm{~mm}=\mathrm{mmol} / \mathrm{kg}$ fluid, $\mu \mathrm{m}=\mu \mathrm{mol} / \mathrm{kg}$ fluid, $\mathrm{nd}=$ not determined

Isotopic composition of $\mathrm{SO}_{4}$ derived from disproportionation of magmatic $\mathrm{SO}_{2}$ prior to seawater mixing.

Concentration of $\mathrm{SO}_{2}$ in end-member magamtic fluid prior to disproportionation. 

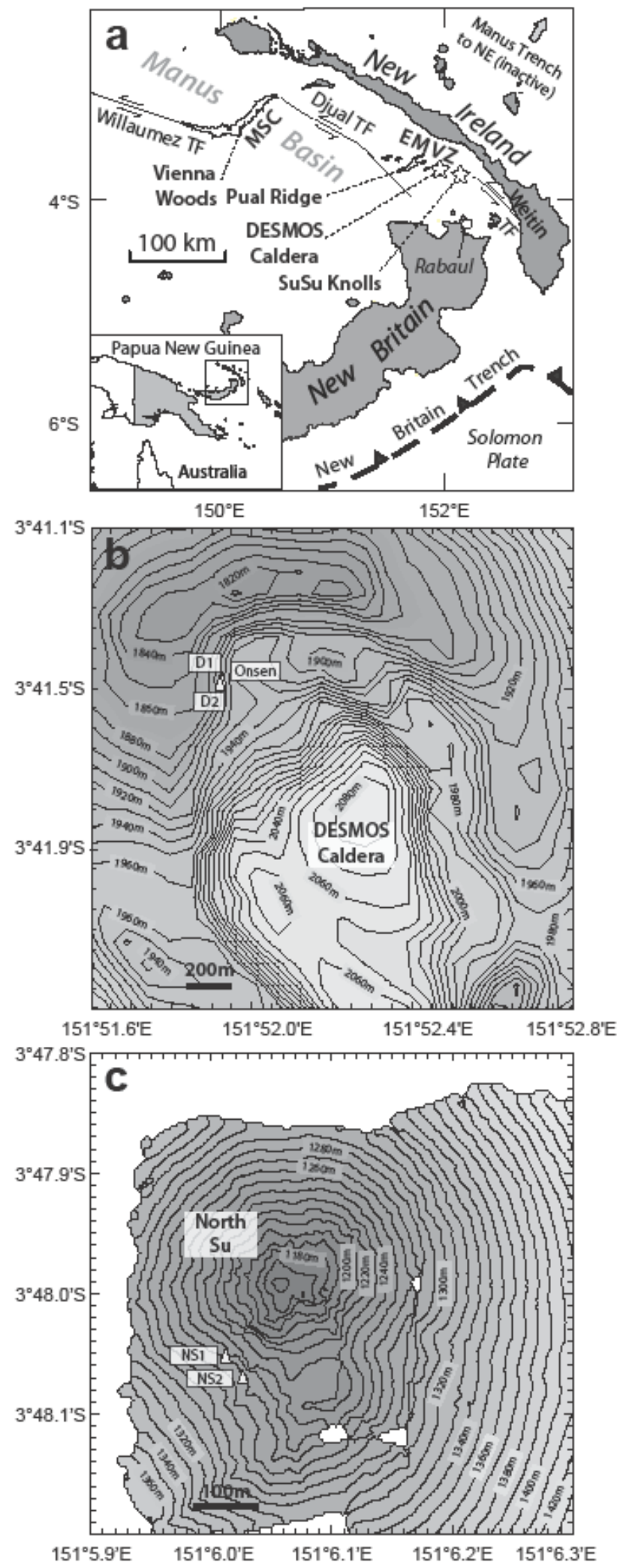

Figure 1. Seewald et al. 

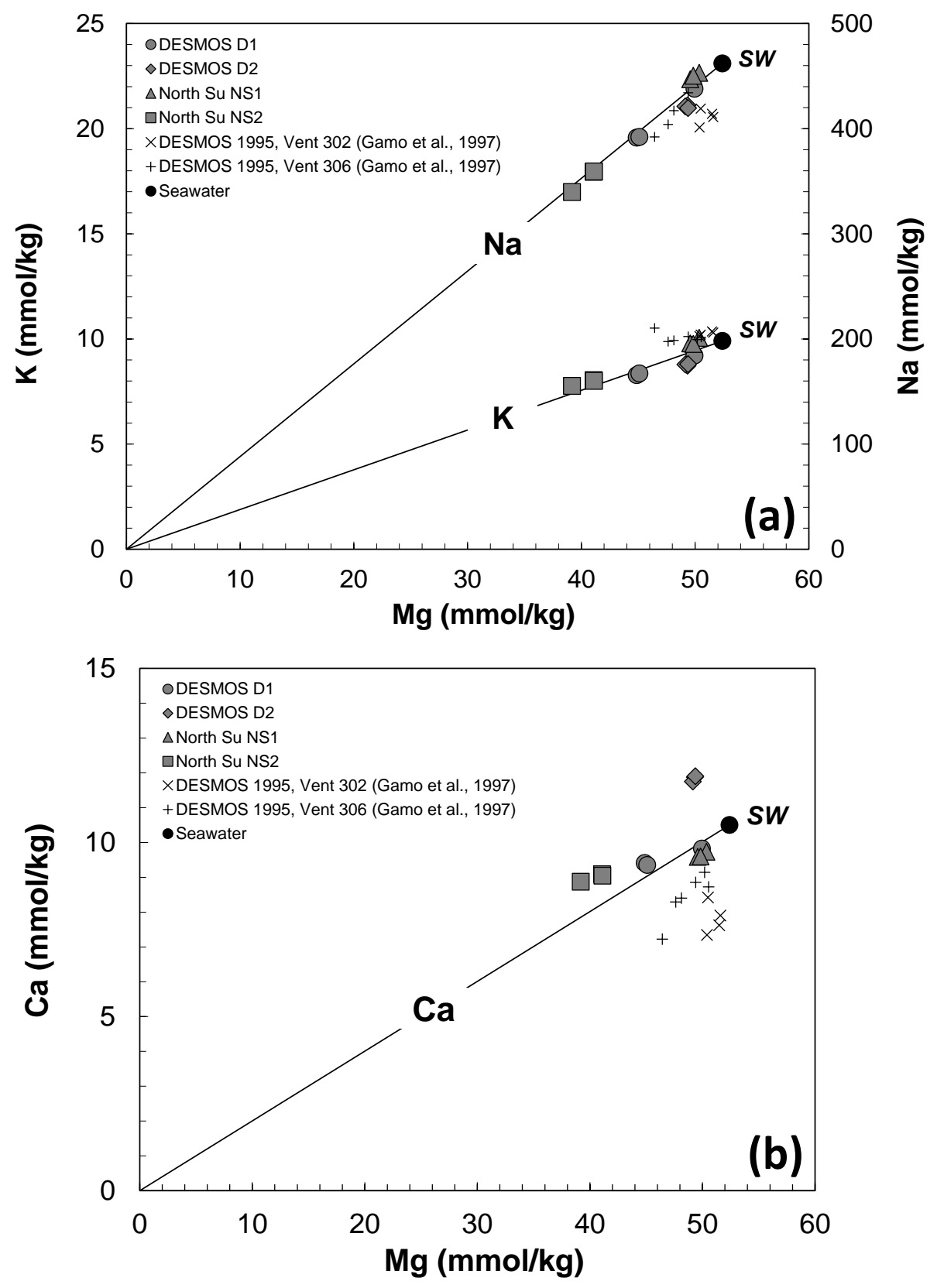

Figure 2. Seewald et al. 

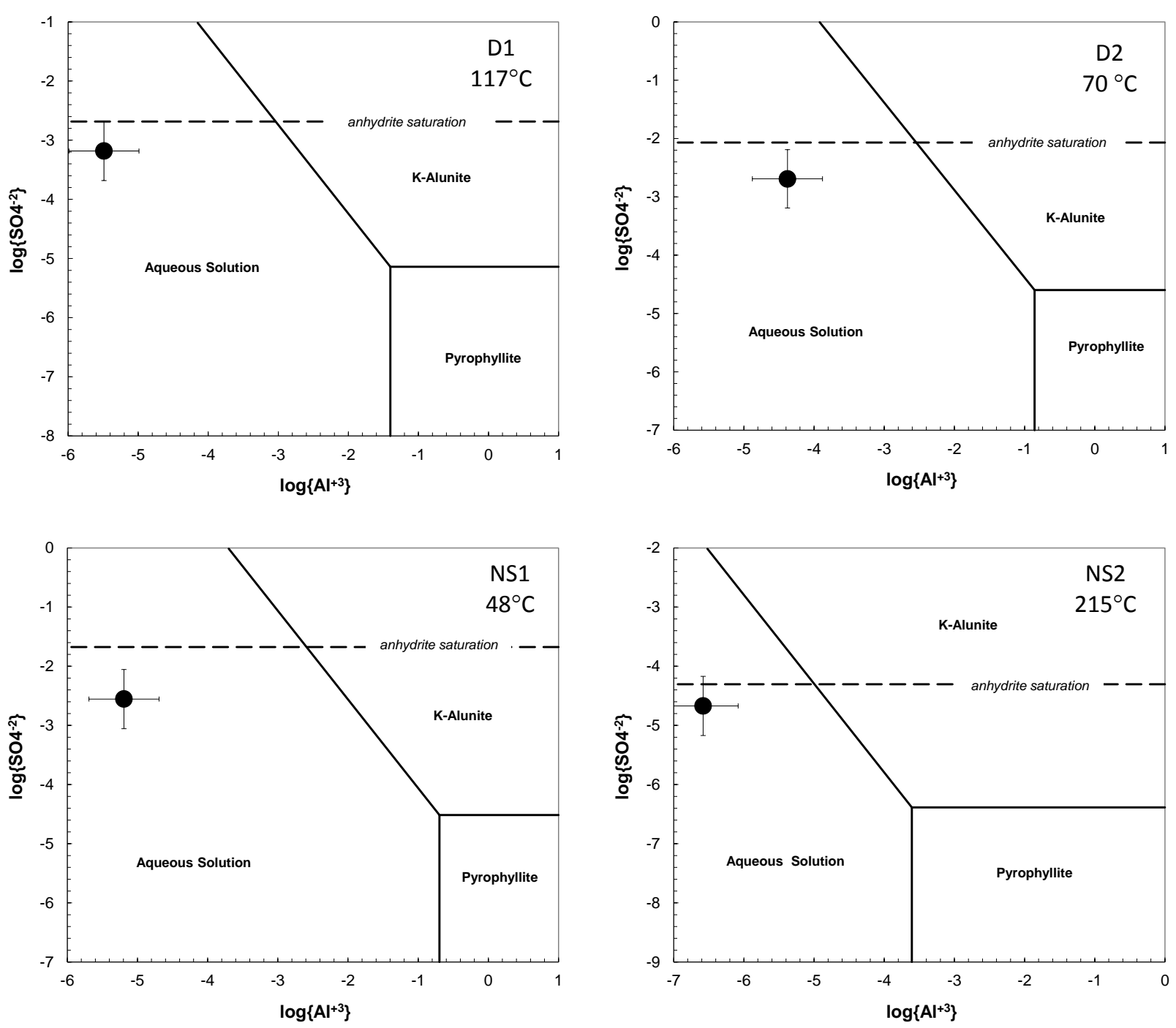

Figure 3. Seewald et al. 

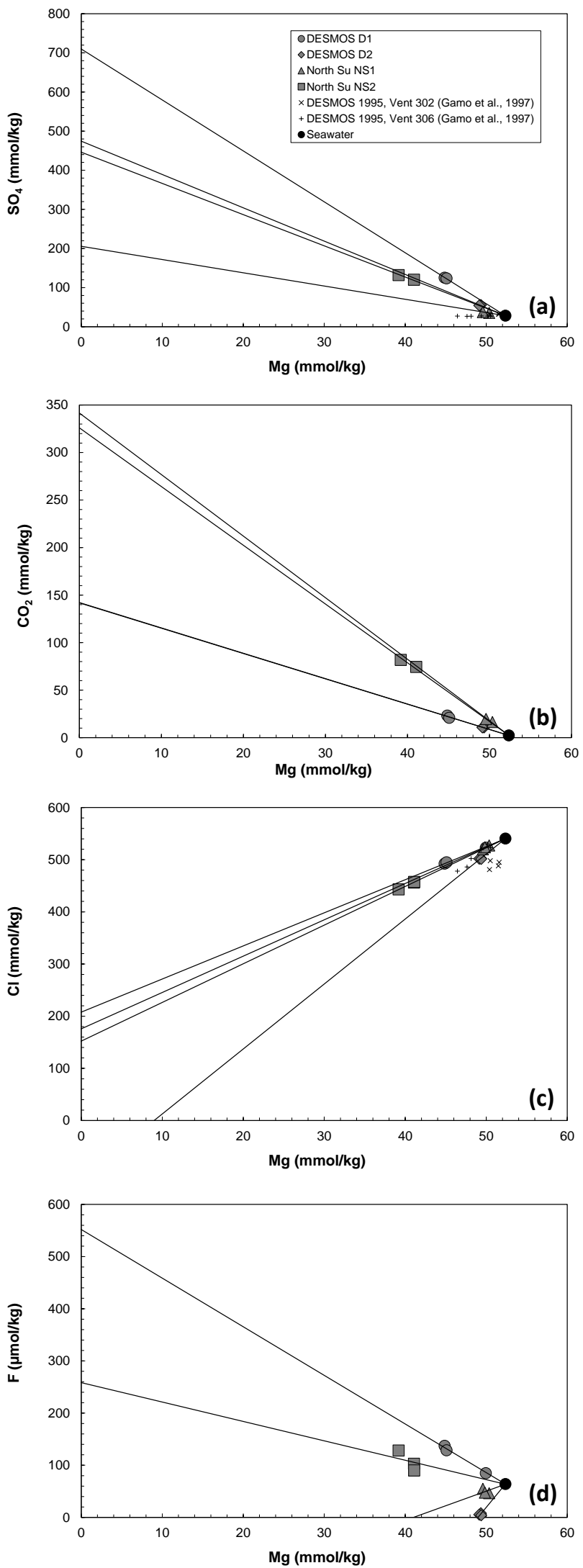

Figure 4. Seewald et al. 


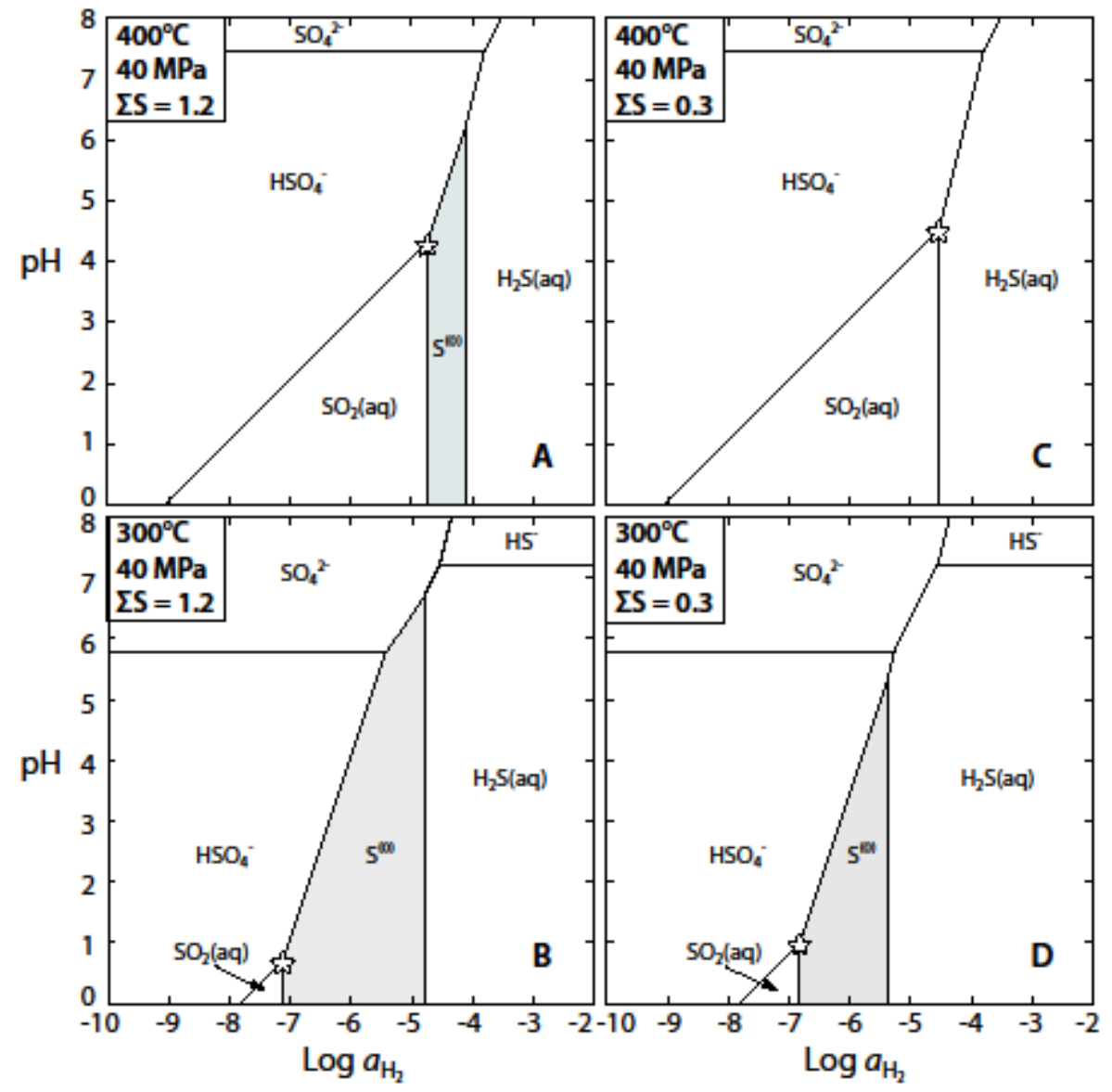

Figure 5. Seewald et al. 


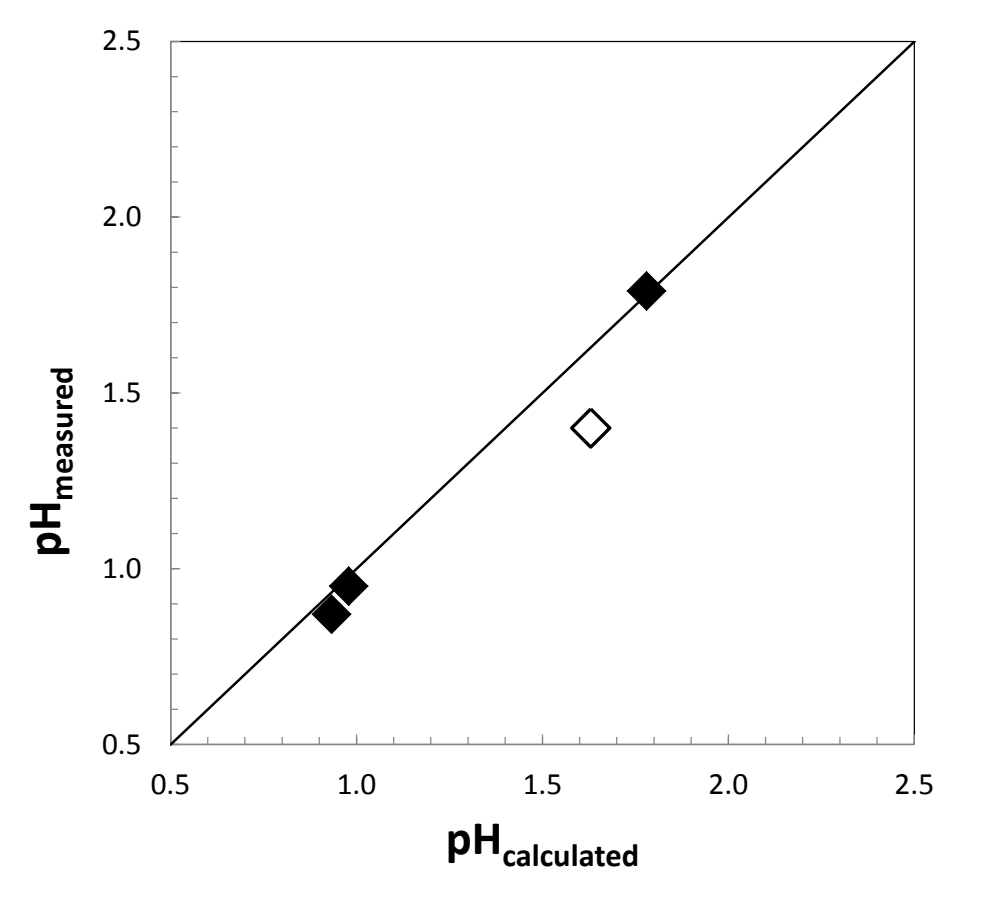

Figure 6. Seewald et al.

Figure

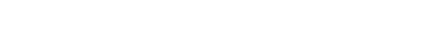

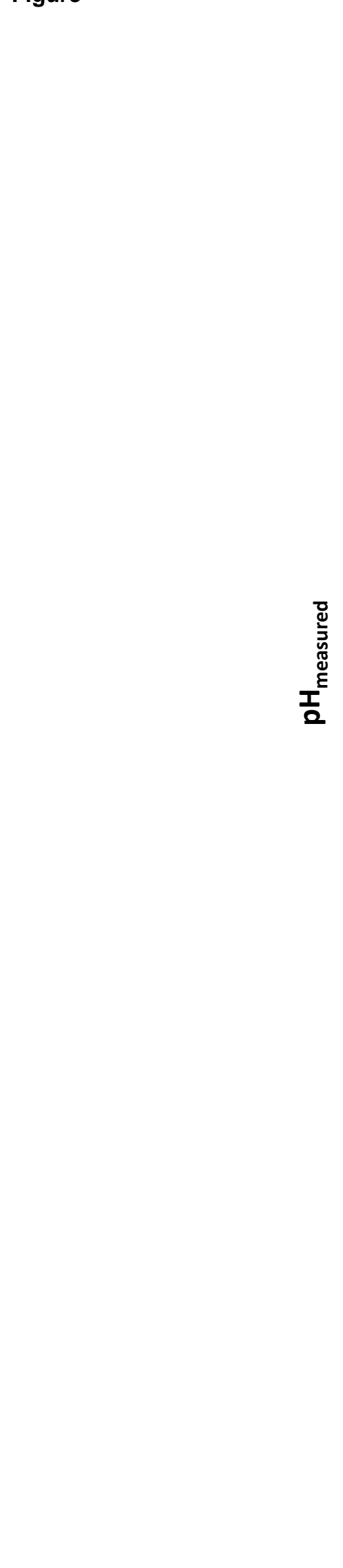

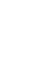




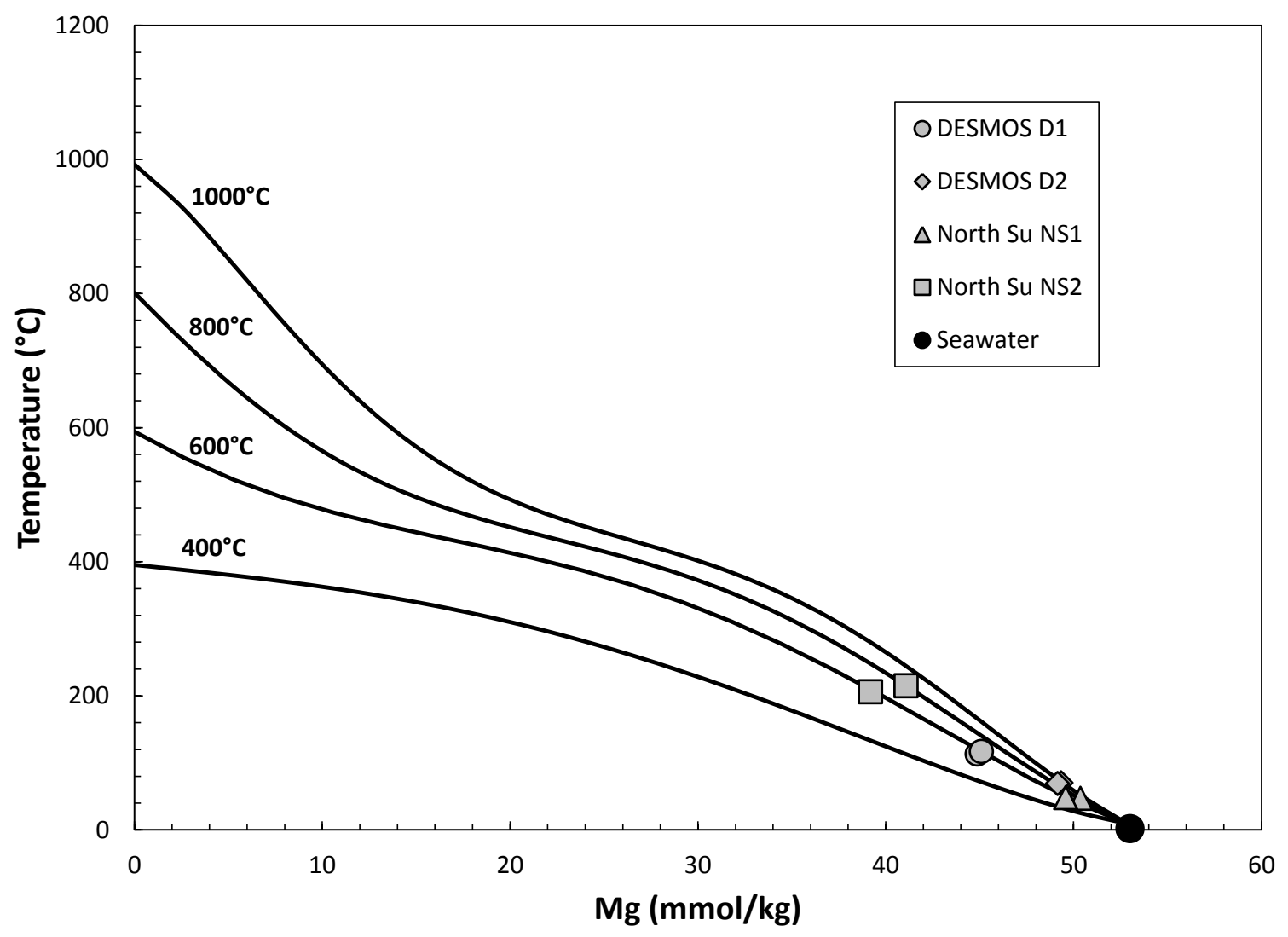

Figure 7. Seewald et al. 


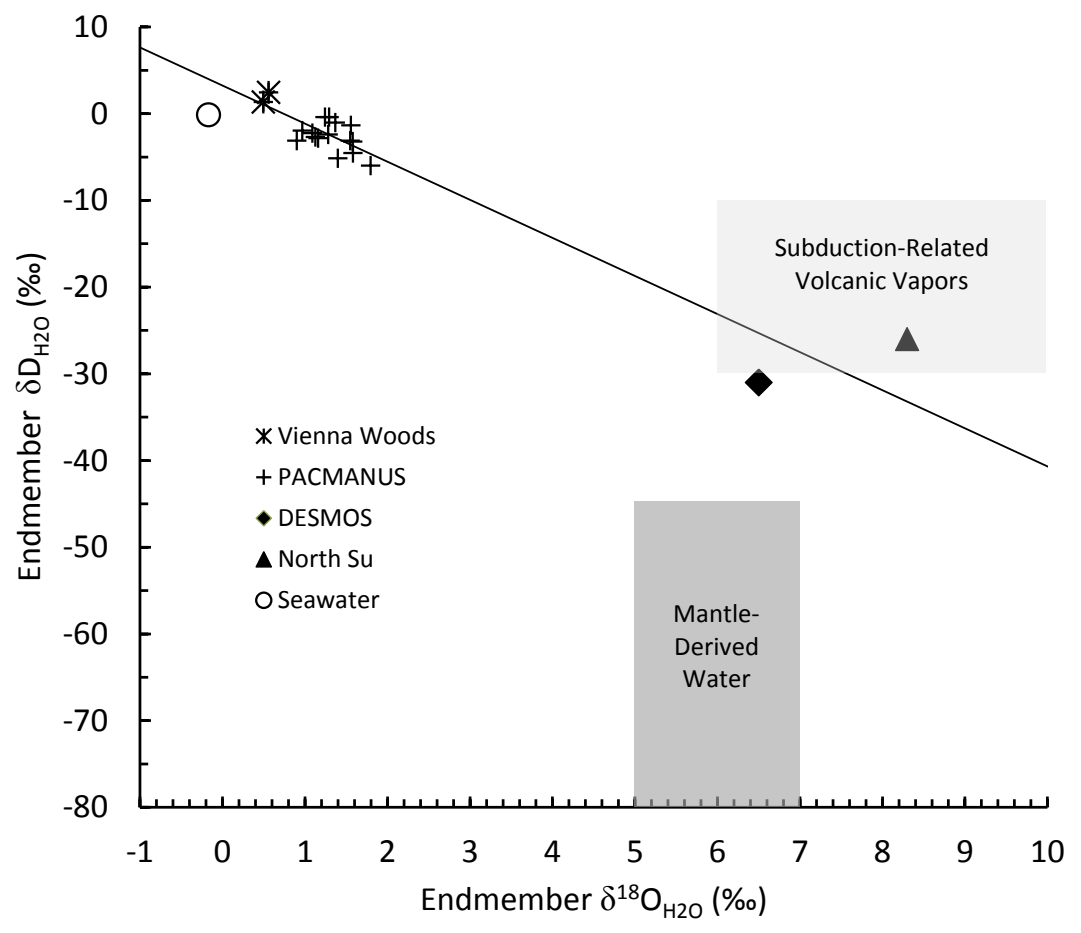

Figure 8. Seewald et al. 